\title{
The Impact of CCN Concentrations on the Thermodynamic and Turbulent State of Arctic Mixed-Phase Clouds
}

\author{
Jan Chylik ${ }^{1}$, Stephan Mertes ${ }^{2}$, and Roel A. J. Neggers ${ }^{1}$ \\ ${ }^{1}$ Institute for Geophysics and Meteorology, University of Cologne, Germany. \\ ${ }^{2}$ Leibniz Institute for Tropospheric Research (TROPOS), Leipzig, Germany
}

Correspondence: Jan Chylik (jchylik@uni-koeln.de)

\begin{abstract}
.
Impacts of aerosol on mixed-phase cloud evolution play a potentially important role in Arctic climate, but remain poorly understood. The way in which aerosol, clouds and turbulence interact, is speculated to significantly modify the cloud evolution. There has been an increasing number of field observations of the ice clouds in Arctic, however it has proven hard to gain insight into these complex interactions using measurements alone. This model study aims to help filling this gap in the current understanding of low-level Arctic clouds, by combining high resolution simulations with new field campaign data. The main focus is on the impact of the cloud condensation nuclei concentration $(\mathrm{CCN})$ on the properties of cloud and mixed-layer turbulence in an evolving boundary layer. We configure semi-idealised model scenarios based on the weather situation observed over open ocean during two research flights of the ACLOUD campaign, which took place over Fram Strait northwest of Svalbard. A demi-Lagrangian frame of reference is adopted, with the model domain following low level air masses and the large-scale forcings derived from weather model analyses and short-range forecasts. Adjustments in the initial state are made based on comparison to dropsonde data. The simulations reproduce the observed general structure of the cloud-bearing Arctic mixed layer. Results further show that while the ice phase forms just a fraction of the mass of cloud water, it is responsible for most of the precipitation, in line with previous observational and LES studies. A lower initial CCN concentration generally results into a faster glaciation of the cloud, leading to a faster removal of the cloud water, and also affects the vertical structure of turbulence. Implications for radiative studies of clouds for the purpose of Arctic Amplification are discussed.
\end{abstract}

\section{Introduction}

The Arctic has experienced since early 1990's more prominent warming than the rest of the world (Walsh and Crane, 1992) (Wendisch et al., 2013). This phenomenon of Arctic Amplification (Serreze and Francis, 2006) has generated a great amount of interest (Holland et al., 2003) (Overland et al., 2016) (Graversen., 2016). While low-level mixed-phase clouds are abundant in the Arctic climate, they significantly affect the surface radiative budget (Tsay et al., 1989) (Liu et al., 2017). Therefore, they are expected to play a very significant role in the Arctic Amplification (Kay et al., 2016). While the widespread melting of sea-ice and opening of leads is likely to lead to changes in the amount and the composition of mixed-phased clouds (Morrison et al., 2012) (Jun et al., 2016) (Chernokulsky et al., 2017), these changes are likely to create feedback loops due to changes in 
the radiative properties of clouds (Tan and Storelvmo, 2019) (Morrison et al., 2019). Although a general increase in the cloud cover is expected (Morrison et al., 2018), the presence of larger ice particles can ultimately enhance the warming rather than reduce it (Vavrus et al., 2011) (Tan and Storelvmo, 2019).

While the importance of the mixed-phase clouds in the radiative balance is established (Morrison et al., 2011), there are various challenges in representing these clouds in numerical weather forecast (NWP) models and climate models (Forbes and Ahlgrimm, 2014) (Kim et al., 2016) (Korolev et al., 2017). Modifications in the representation of clouds can often lead to strong changes in the magnitude of warming (Kay et al., 2016). The models are particularly sensitive to representation of ice phase and optically-thin clouds (Simjanovski et al., 2011) (Cesana et al., 2012) (Hashino et al., 2016). The currently used parameterizations of cloud processes are often based on better explored systems from lower latitudes, which are likely not very representative of the situation in the Arctic (Vihma et al., 2014). These parameterizations then often underperform (Barton et al., 2014) (Hashino et al., 2016) (Cassano et al., 2017) (Pithan et al., 2018) (Lacour et al., 2018) because of the lack understanding of the physical processes and interactions (McIlhattan et al., 2017). Not only the parameterizations of mixed-phase clouds here do not yield suitable results, the underlying scientific knowledge of these clouds is often insufficient. This is partially caused by the lack of suitable measurements in the area, as well as biases in the satellite observations (Schweiger et al., 2002) (Blanchard et al., 2014) (Khanal and Wang, 2001).

The need for better understanding of mixed-phase clouds and aerosols has motivated an increasing number of field observations focused on the low-level clouds in the Arctic (Curry et al., 1997) (Curry et al., 2000) (Zamora et al., 2017) (Jones et al., 2018), which have been soon followed by modelling studies (Brümmer, 1999) (Khain et al., 2001) (Gryschka and Raasch, 2005) (Klein et al., 2009) (Stevens et al., 2018). There has been also steadily growing number of studies that examine the impact of microphysical processes on the evolution of Arctic clouds (Morrison et al., 2011) (Fridlind and Ackerman., 2018) (Norgren et al., 2018). Some studies have assumed fixed values of cloud droplet number and cloud ice number concentrations (Young et al., 2018) (Kaul et al., 2015). Other have considered the explicit nucleation of cloud droplets in cloud ice (Jackson et al., 2012) (Solomon et al., 2018) (Fu et al., 2019) with rates depending on the concentration of aerosols acting as cloud condensation nuclei $(\mathrm{CCN})$ and ice nucleation particles (INP).

While the aerosols in lower latitudes modify cloud fraction, optical depth of warm clouds (Gryspeerdt et al., 2016), and also the vertical velocity (Dagan et al., 2016), including cloud-aerosol interactions generally improves the representation of warm clouds (Sotiropoulou et al., 2019). However the situation is Arctic is more complicated due to the thinner cloud layers and co-existence of ice and liquid phase (Verlinde et al., 2007). Furthermore, there is often a complicated system of microphysical processes in the sub-cloud layer (Qiu et al., 2018). In general, aerosols in the Arctic exhibit a significant effect on cloud fraction, as well on precipitation (Zamora et al., 2018). There are indications that higher number of aerosols lead to decrease in precipitation (Lance et al., 2011), while the low aerosol concentrations limit the growth of clouds (Stevens et al., 2018). 
Simulations based on Arctic field campaign data are often simplified in key aspects. This is particularly true for cloudaerosol interaction — on one hand, the importance aerosol in microphysical processes has been strongly indicated (Zamora et al., 2017) (Ickes et al., 2018). On the other hand, model studies usually do not take into account a high variability in aerosols concentrations, which are common in the Arctic (Kalesse et al., 2016) (Willis et al., 2019). The aerosol composition and cloud properties often vary with the direction that the air originates in (Qiu et al., 2018). Aerosols are often transported to Arctic from distant sources (Sand et al., 2017) and undergo changes due to chemical and precipitating processes (Norgren et al., 2018). The modification of aerosol composition due to cloud processes has been observed (Várnai and Marshak, 2011). Yet, these phenomena are rarely considered in the construction of model cases.

In this paper the impact of $\mathrm{CCN}$ concentrations on the evolution of mixed-phase clouds and turbulence is investigated using a combination of observations and Large-Eddy Simulations (LES). Two semi-idealised Lagrangian cases are constructed based on observations during the Arctic CLoud Observations Using airborne measurements during polar Day (ACLOUD) field campaign, which took place in the Fram Strait in Spring 2017. One case describes a weak Cold Air Outbreak (CAO), the other a cloud situation over open water. Measurements used to construct the cases include dropsonde profiles and in-situ aerosol datasets. Unlike many previous LES studies, the number concentration of cloud droplets and the concentration of cloud condensation nuclei are not prescribed parameters but are prognostic. This allows us to take into account the transport of CCN and their consumption by precipitating processes. With this modelling system the evolution of mixed phase clouds during the two cases is investigated, with the aim of gaining more insight into interactions between aerosol, clouds and turbulence in the Arctic. The relatively rapid growth of clouds in both case cases allows us to evaluate impacts of microphysical properties on relatively short timescales.

80

Studying Arctic clouds in the Spring season is motivated by their significant sensitivity to aerosol concentrations (Fan, 2013) and the size of ice particles (Mioche et al., 2017). Also, in this season the ice phase tends to exhibit a weak dependency on the temperature, and often features high quantities of supercooled droplets (Cox et al., 2014). Moreover, significant variations in aerosol concentrations are typically observed during Spring (Willis et al., 2019). With decreasing sea-ice in a warming Arctic climate such variations are likely to increase (Bigg and Leck, 2008), which in turn is also affected by clouds themselves (Cox et al., 2016).

The first part of the paper focuses on the ACLOUD field campaign, providing information about the weather situation in general, the airborne and ground measurements, and the flight days selected for simulation. The construction of the semi-idealised model scenarios is then described in detail, including the model setup and the microphysics scheme, as well as the method adopted to analyse the model results. Various sensitivity runs on model resolution and other parameters are also addressed. Next results are presented of the control runs and its evaluation against dropsonde observations, followed by an interpretation of sensitivity runs on the initial CCN concentrations. For all experiments the impact of microphysical processes on the budget of cloud water is investigated in detail, as is the behaviour of turbulence and entrainment. In the presentation of the results both 
cases are always compared to assess general behaviour. The discussion focuses among others on the choice of investigating CCN over INP, and on possible limitations of this study. Finally some concluding remarks are given, and the implications of the obtained results for future studies is briefly discussed.

\section{Observations}

\subsection{Field Campaign}

The ACLOUD field campaign took place from 23 May to 26 June 2017 in the vicinity of Svalbard. Together with its sister campaign, Physical feedbacks of Arctic planetary boundary level Sea ice, Cloud and AerosoL (PASCAL), that were organised as part of the ongoing Arctic Amplification: Climate Relevant Atmospheric and Surface Processes and Feedback Mechanisms $\left((\mathcal{A C})^{3}\right)$ research program (Wendisch et al., 2017). Both campaigns provided valuable observations of Spring-time lower troposphere. ACLOUD was characterised by collocated airborne observations performed by aircraft Polar 5 and Polar 6 (Wendisch et al., 2018). In the following paragraphs, we will first briefly summarise specifics of this campaign. Secondly, we will focus of the choice of field days for further observations. Then we will discuss the observations of aerosols concentrations and their importance as a proxy for estimating the range of $\mathrm{CCN}$ concentrations.

The time span of the ACLOUD campaign covered three distinct regimes in synoptic conditions (Knudsen et al., 2018). The first campaign week was characterised by the advection of cold and dry air from the north. This resulted into prevailing low-level clouds over open water. During the following two weeks, the prevailing air masses originated from south and east. The lower troposphere was significantly warmer and moister, with variations in the cloud cover. The final 2 weeks were then affected by air masses from west, which lead to further variations in cloud cover and temperatures in the mid-troposphere. Airborne observations were performed in both in stable stratified and convective conditions, in a shallow single-layer clouds, multi-layer clouds, but also in clear-sky conditions.

\subsection{Flight Days}

From the number of weather situations observed during the ACLOUD, we have carefully selected two cases of of clouds driven by convection (see Figure 1). While each of these cases on its own is an interesting example of low-level clouds, together they provide more robust insight into the evolution of mixed-phase clouds near the sea-ice margin in Spring in the Arctic. In the following paragraphs, we will briefly describe the chosen flight days and provide justification for their selection for further investigation. 


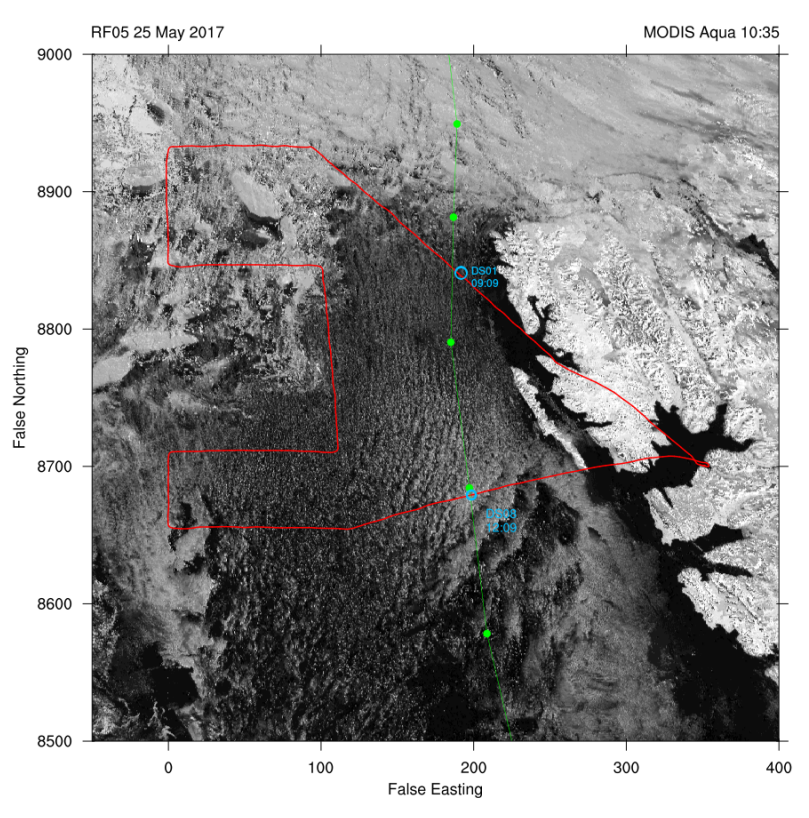

(a)

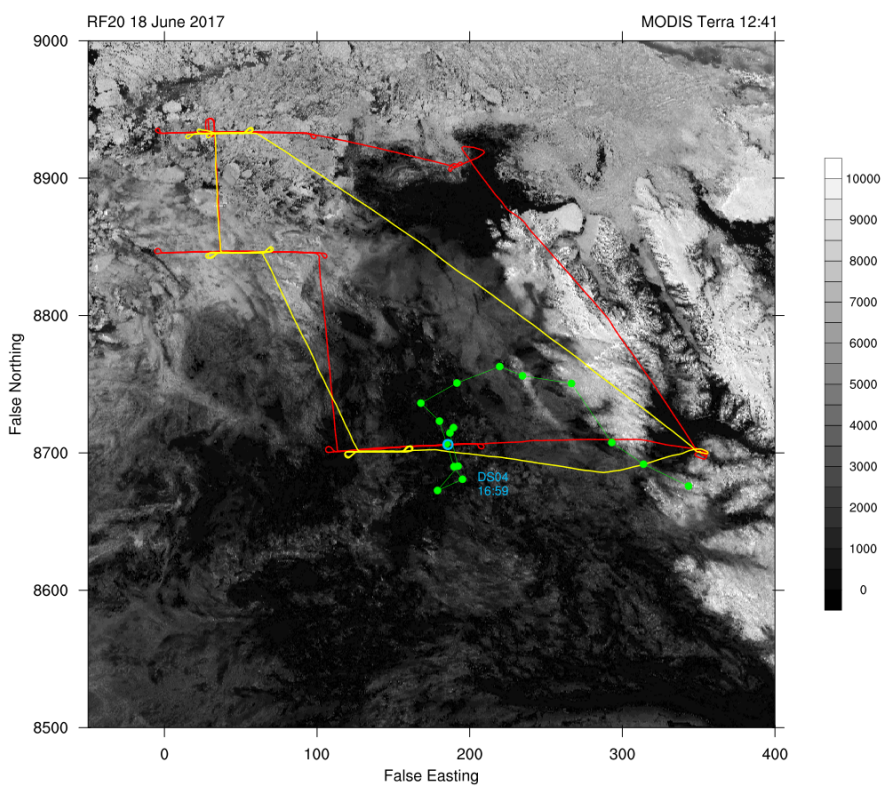

(b)

Figure 1. Mesoscale weather situation during a) RF05 and b) RF20 — The Svalbard land mass shows up in bright white on the right, while the sea ice is visible as grey areas in the top-left and top. The flight track of Polar 5 (red), Polar 6 (yellow), and the trajectory of the simulated domain (green) overlaid over the MODIS band 1 reflectance. The ACLOUD dropsondes (DS) used for case configuration are indicated in blue, indicating their UTC time of release. (Data was obtained through NASA Earthview)

The mission day RF05 was concerned with the observation of a cold-air outbreak (CAO) developing over Fram Strait northwest and west of Svalbard. The advection of the cold air on 25 May 2017 then leads to a development of a typical CAO scenario (Chechin and Lüpkes, 2017) west of Svalbard. The convective rolls started forming over marginal sea-ice zone (MIZ) northwest of Svalbard. This was followed by the formation of cloud streets, which continued downwind for more than $400 \mathrm{~km}$.

During RF05, the Polar 5 released dropsondes at various locations, including shallow boundary cloud streets not far of the edge of ice, as well as the deeper cloud streets further south. The backward projection of air parcel trajectories (to be discussed in section 3.3) suggests that dropsonde DS08 and dropsonde DS01 of the edge of ice approximately sampled the same air mass. This provides us with a unique opportunity to address the bias in the boundary layer depth and temperature in the ECMWF forecast. The correction of the initial state of the boundary layer is described in section 3.4.

The mission RF20 took place on 18. June 2017 over the open water of Fram Strait west of Svalbard. The prevailing synopticscale situation was similar to the situation in preceding days. However there had been a slight decrease in the humidity of the 
advected air in mid troposphere, resulting into disappearance of cirrus clouds from previous days (Knudsen et al., 2018). RF20 differs from RF05 in that i) the air mass is much slower moving (see Figure 1) and ii) the air mass originates over open water already and is much warmer.

Overall, RF05 presents an illustrative example of a CAO with a gradual deepening of the Arctic mixed layer (AML). There is a single layer of low-level clouds and the atmosphere above is virtually cloud-free. This allows us to investigate a relatively simple case of mixed-phase clouds in initially cold and dry air that is then modulated by convection and radiative cooling. RF20 then provides a "counterexample", a warmer weather situation with a weak convection is dominated by a thicker layer of low-level clouds that continue deepening.

\subsection{Aerosol Measurements}

The instruments during the ACLOUD campaign included probes with the aerosol mass spectrometer for sampling submicronsize particles aboard the Polar 6 aircraft (Ehrlich et al., 2019). The ultra-high sensitivity aerosol spectrometer (UHSAS) measured the number size distribution of particles with diameters between $60 \mathrm{~nm}$ and $1000 \mathrm{~nm}$ by detecting scattered laser light. For further description we refer to Cai et al. (2008). The observations of aerosols particles were often collocated with the cloud radiative measurements (Wendisch et al., 2018) - i.e. on some of the flight legs over the Fram Strait, Polar 6 with aerosol probe and Polar 5 with radiative instruments flew parallel to each other at different altitudes.

Due to various technological and logistical challenges faced by Polar 6 during the ACLOUD campaign, aerosol measurements are unfortunately not available for chosen flight days. However, an extensive airborne sampling of aerosols was performed less than 44 hours after RF05, during RF07 on 27 May, when the weather situation was still dominated by the advection of the same air masses (Knudsen et al., 2018). Similarly, the large-scale weather conditions for RF20 on 18 June were very similar to those on a previous day during RF19 flight, which also shared a similar flight path. While it is possible that the distributions of aerosols have changed, we expect a similar range of aerosols concentrations.

During RF07 and RF19, Polar 6 sampled aerosols at various altitudes. This included both horizontal flight legs at altitudes between $60 \mathrm{~m}$ and $3000 \mathrm{~m}$, as well as profiling flight legs. However, the probe was usually not recording in the clouds due to danger of icing. Most of the trajectory was in the free atmosphere, while the lower legs were performed only in the specific areas of interest. Aerosols sampling from 17 June (see Figure 2b) shows a wide range of aerosol concentrations. While the range of concentrations of aerosol particles of sizes $100-150 \mathrm{~nm}$ is increasing with altitude, the concentration of particles larger than $150 \mathrm{~nm}$ show similar ranges at all recorded altitudes. in the bottom $1400 \mathrm{~m}$ meters, followed by a wide range of concentrations above. To distinguish between the properties of 


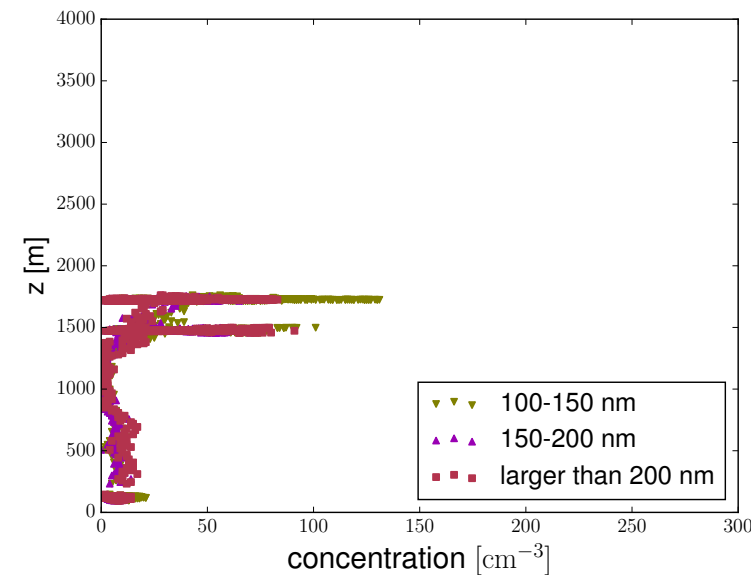

(a)

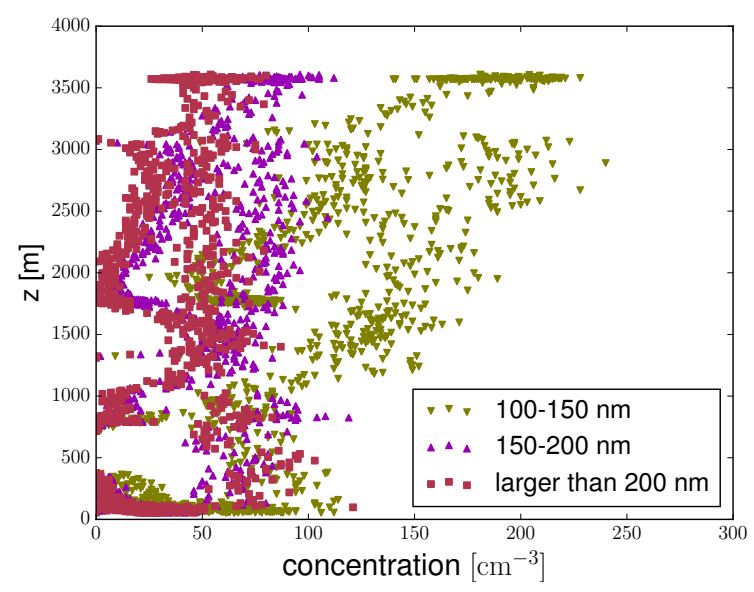

(b)

Figure 2. Observed aerosols concentrations from aerosol mass spectrometer aboard Polar 6 (Mertes et al., 2019) at different altitudes on a) 27 May and b) 17 June. Recorded particles were divided into size categories: 100-150 nm, 150-200 nm, and larger than $200 \mathrm{~nm}$. Size categories are in the scatter plots distinguished by colour.

atmosphere in different areas, we evaluate the statistical distribution in each of them. The ranges of aerosols concentration shown in the figure 3 are then utilised in the setup of model ensembles (3.5).

\section{Methodology}

The observed weather scenarios serve as starting point for the construction of semi-idealised LESs. With the aim to follow the evolution of Arctic clouds in the cold outbreak, we follow the trajectory of an air parcel in a demi-lagrangian frame of reference (Neggers et al., 2019). The initial conditions, large-scale forcings and surface conditions are set to closely follow analyses, short-range forecasts and and observations.

The description of Methodology is divided as follows: firstly, we explain the general framework for semi-idealised LES with a demi-lagrangian frame of reference. Secondly, we focus on the bulk microphysics scheme that is has been extended for aerosols. Then we provide further information on the setting of the model ensembles.

\subsection{DALES}

The LES software package used in this study is the Dutch Atmospheric Large Eddy Simulation (DALES), formulated in Heus et al. (2010). DALES has been successfully employed in number of model studies of boundary-layer clouds in subtropics (De 


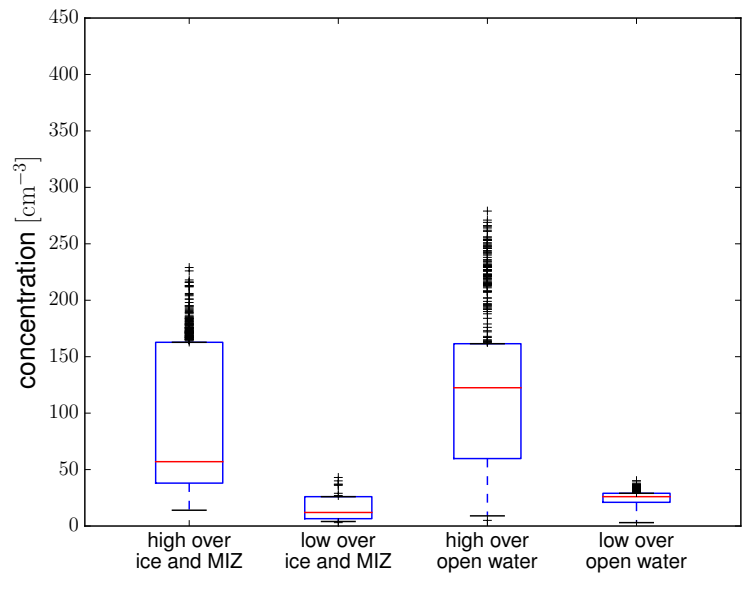

(a)

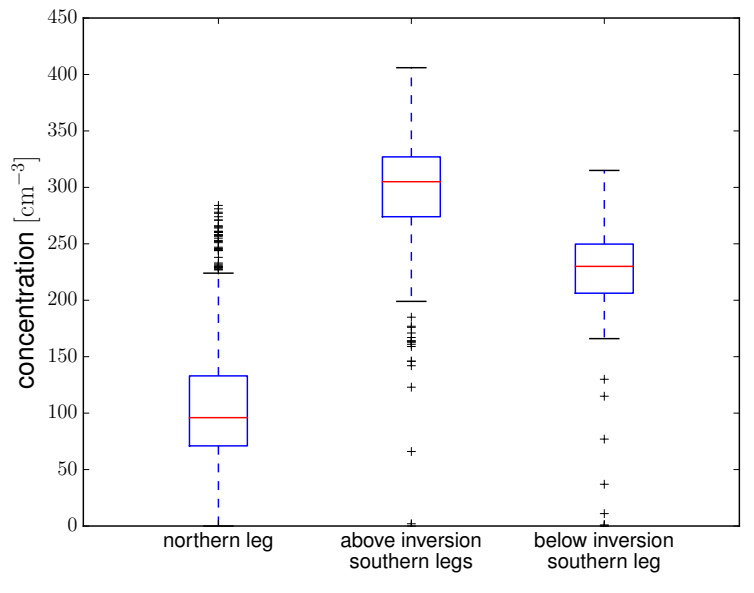

(b)

Figure 3. The statistical distribution of observed aerosols concentrations under various conditions on a) 27 May and b) 17 June. The recorded timeseries of aerosols concentrations were divided into segments based on the area and the altitude of the flight leg they were recorded in: a) data from 27 May are divided into segments: over the sea-ice and MIZ, as well as over the open water in the middle part of Fram Strait; both at altitudes below and above $1400 \mathrm{~m}$; b) data from 17 June are divided into segments: over the northern part of Fram strait, and over southern/central part of Fram strait; further divided for below the strong inversion present at altitude 1500-1900 m, and above it. Boxes indicate interquartile range of the observed distribution of aerosols, while whiskers indicate standard 1.5 range.

Roode et al., 2012), mid-latitudes (Corbetta et al., 2015) (van Laar et al., 2019), as well as polar areas (Neggers et al., 2019). It was also widely used and in studies of neutral boundary layers (Ouwersloot et al., 2016) as well as stable boundary layers (Tomas et al., 2015). Furthermore, the scalability of DALES allow it to be utilised for simulating with various domain sizes (Griewank., 2018) DALES has taken part in various model intercomparison studies, such as stratocumulus-cumulus transition (Dussen et al., 2013) (de Roode et al., 2016) and the CONSTRAIN experiment (de Roode et al., 2019) of the GRAYZONE project.

\subsection{Demi-lagrangian Frame of Reference}

As recently argued by Pithan et al. (2016) and Neggers et al. (2019), the main motivation for doing adopting a Lagrangian configuration in the Arctic is that air masses evolve very slowly, in an area where dense networks for estimating boundary conditions and lateral forcings is totally absent Firstly, a model domain with a separate conditions on the inflow and the outflow would require detailed boundary conditions for the whole time period. Secondly, a clear benefit of Lagrangian setup is that lateral advective forcings become zero in the air mass of interest, which significantly reduces the impact of uncertainties in the estimate of such forcing terms. Thirdly, a spatial domain that would include both the area over sea-ice as well as downwind over the open water would be extremely large for any practical computational purposes. With an aim to follow the evolution of 
convective clouds in the Arctic, the model is set in a demi-lagrangian frame of references.

In this demi-Lagrangian study we follow an 'air parcel' that is advected from over a cold surface (e.g. sea ice) to over a relatively warm surface, e.g. MIZ or open water. The word "demi" here refers to the fact that the whole domain moves with the low level flow; this means that above the mixed-layer inversion, the movement vector can differ from the actual wind at those altitudes. The spatial (and temporal) changes in the surface condition along the trajectory of the moving air parcel are replaced by the temporal changes in surface conditions with time. Similarly, spatial changes in advective tendencies in the free atmosphere along the trajectory are replaced by large-scale tendencies dependent on time and altitude. The Lagrangian approach has been widely used outside the Arctic - there have been various examples of "small domain simulations in a frame of reference moving with the mean wind have been used to explore some aspects of the evolution of roll convection" (Liu et al., 2004). Despite some degree of simplification, model studies with periodic boundary conditions and a moving frame of reference have demonstrated their usefulness in the studies of convective systems (Richardson et al., 2007).

In this study, we implement demi-Lagrangian approach similar to the method used for subtropical marine cloud transitions by Bretherton et al. (1999). An issue of this method is that it does not capture the effect of the different advection speeds due to shear within the AML. However, this issue is of a minor importance when the AML is well-mixed. Although the aforementioned approach was originally used for the boundary-layer transition in tropics, it has recently also been applied for high-latitude conditions. Examples include, amongst other simulations of a large CAO over Gulf stream where the wind velocity is not constant with height (Skyllingstad and Edson, 2009), or simulations of shallow Arctic mixed layer (Neggers et al., 2019).

\subsection{Back-trajectories}

The starting step in the configuration of a case with moving frame of reference is determining the movement of the investigated air parcels. The dropsonde launches during RF05 and RF20 serve as a starting time and location for back-tracking the parcel movement. While the focus is on the air masses in the lower troposphere, we follow the air mass at the level $950 \mathrm{hPa}$ upstream based on large-scale NWP data. The large-scale data is obtained from the products of Integrated Forecasting System (IFS) of the European Centre for Medium-range Weather forecasts (ECMWF).

For more details on this approach, we refer to Neggers et al. (2019), and will only briefly be summarised here. A combination is used of IFS analyses (available every 12 hours) and short-range forecasts (available every 3-hours), which effectively yields a four-dimensional dataset of the atmospheric state variables at 3-hourly temporal resolution and $0.1 \times 0.1$ degree spatial resolution. Horizontal advective forcing is represented through prescribed advective tendencies, calculated through horizontal averaging within a $0.5^{\circ} \times 0.5^{\circ}$-wide column around the location of interest. The forcings are estimated at points along the trajectories, with the wind velocity at $950 \mathrm{hPa}$ being subtracted from the wind profiles in the calculation of the advective 
tendencies. Vertical large-scale advection is represented using a prescribed subsidence profile, by which advection becomes interactive with the simulated vertical gradients. The subsidence profile is linearized between the thermal inversion $z_{i}$ and the surface (Sandu and Stevens, 2011) (Neggers et al., 2017) (Loewe et al., 2017) (Sotiropoulou et al., 2018).

\subsection{Adjustment of Initial Conditions}

Most weather prediction and climate models tend to overestimate the boundary-layer depth over the sea-ice (Makshtas et al., 2007) (Jakobson et al., 2012) (Wesslén et al., 2014) (de Boer et al., 2013) (Lindsay et al., 2014). While the trajectory of air parcel in RF05 case starts over sea-ice, it likely suffers from the same problem. With a goal to correct for the possible bias in model scenario, we focus on the independent observational data. The back trajectory of air masses from dropsonde DS08 is passing in the vicinity of previously released dropsonde DS01 (see Figure 1). This allows us to confront the thermal inversion heights extracted from the ECMWF forecast with the dropsonde sampling. The correction of the inital thermodynamic profiles and the surface conditions over the sea-ice follows the iterative method of "microgrids" described in detail in Neggers et al. (2019). Figure 4.a shows that the modelled altitude of inversion is significantly higher than in the dropsonde soundings DS01 and DS08.

For the RF05 case the initial conditions are adjusted as follows: Based on the observed inversion height at DS01 the height of the inversion in the initial state is lowered to $500 \mathrm{~m}$. Below that height the temperature is reduced by $4 \mathrm{~K}$, again inspired by comparison to DS01 and DS08, while the total specific humidity is adjusted such that the relative humidity is conserved within the mixed layer. Furthermore, between the old and new mixed layer height the temperature gradient is extrapolated downwards, humidity is set constant at free tropospheric values, and any cloud condensate is removed (Neggers et al., 2019). Finally, the skin temperature over sea-ice is similarly adjusted by $-4 \mathrm{~K}$. After this correction, the inversion heights generally agree with said soundings (see Figure 4.b).

\subsection{Microphysics}

The DALES code was modified to include the extension for the full mixed-phase microphysics based on Seifert and Beheng (2006a). The scheme then treats subsaturation and supersaturation by the standard saturation adjustment which takes place after the collection and conversion microphysical processes (Seifert and Beheng, 2006b). This parameterisation scheme has been utilised in a number of numerical models of atmosphere. These are for example LESs such as UCLA-LES (Ackerman et al., 2009) or DALES, and mesoscale models such as ICON (Heinze et al., 2017), albeit in a modified form. A number of implementations of this parameterization scheme has been slightly simplified. A common adjustment is such that clouds are represented by only one moment while the cloud droplet number concentration is defined as a constant parameter depending on the environment (Ackerman et al., 2009) (de Roode et al., 2019). This is also the case of the current default version of DALES, where only the warm part of the microphysics scheme is included (Heus et al., 2010). 


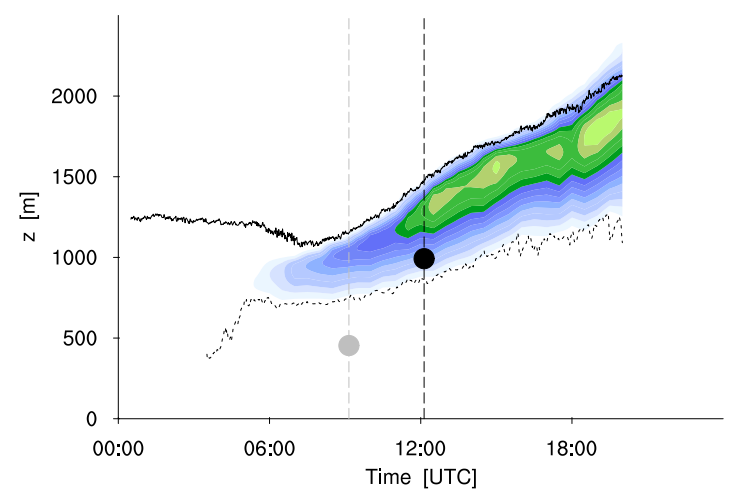

(a)
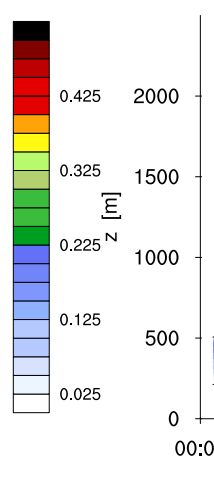

00:00

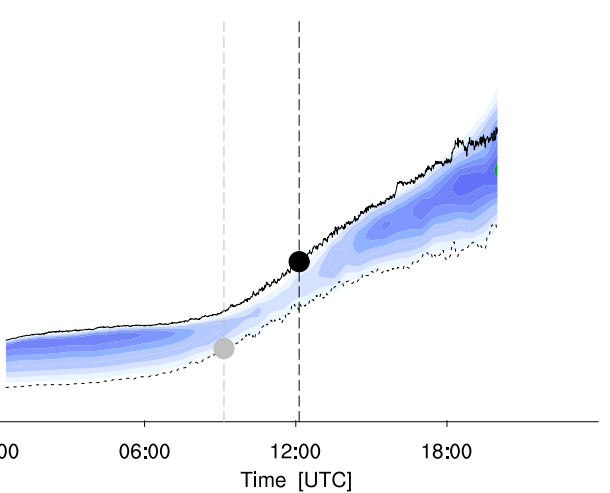

(b)

Figure 4. The comparison of microgrid runs, a) initialised by the original weather forecast data, and b) after the correction. The grey line indicates the launch of the dropsonde DS01, while the grey dot indicates the altitude of the steepest gradient in the potential temperature sounding. The black line and black dot then indicate the launch of DS07 and the steepest gradient there. Contourplots indicate modelled $q_{c l}$, the specific liquid cloud liquid water content, in $\mathrm{g} \mathrm{kg}^{-1}$.

In this modified version of DALES, the formulation of the the 2-moment bulk scheme is closely followed in the extension cloud droplet number is treated as a prognostic variable and the cloud nucleation is calculated explicitly. We further enhance this scheme by treating the $\mathrm{CCN}$ number concentration as a prognostic variable. The activation of $\mathrm{CCN}$ is calculated prognostically in the saturated grid cells. The CCN concentration is conserved during the processes of nucleation of cloud droplet, their condensational growth and evaporation. The self-collection of cloud droplets and precipitating processes then act as a sink for $\mathrm{CCN}$. In the absence of a more advanced CCN formulation that would be compatible with 2-moment scheme, the collection of cloud droplets by ice particles and the freezing of cloud droplets are for simplicity treated as simple loss terms. Nevertheless, the glaciation of clouds here does not lead to depletion of $\mathrm{CCN}$, since majority of smaller cloud droplets evaporate due to the decrease in water vapour pressure caused by the vigorous growth of ice crystals.

The value of the $\kappa$ parameter in the $\mathrm{CCN}$ activation relation is set to the standard value for maritime conditions (Khain et al., 2001). The microphysical parameters $a, b, \alpha, \beta, \mu$ and $\nu$ are set to the values presented in table 1 . The majority of parameters follow the standard setting of Seifert and Beheng (2006a) with the exception of the values of the parameters for cloud ice, which were adjusted to the same values as in the model intercomparison study of clouds in cold climates (de Roode et al., 2019) to better suit the conditions. The diversion from the standard setting is justifiable since the original setting was based on the high-altitude clouds in storms in temperate climates (Seifert and Beheng, 2006b).

The choice of the the initial values of $\mathrm{CCN}$ concentrations is constrained by the observation aerosols 2.3. In both cases, we assume that between $50 \%$ and $90 \%$ observed in the parcel starting area can act as CCN. In the case of RF05, the parcel is starting in the are over ice and MIZ. The starting are of RF20 is below the inversion in the southern leg. While we do not want 
Table 1. Overview of setting microphysical parameters for hydrometeors

\begin{tabular}{lccccccc}
\hline & $a$ & $b$ & $\alpha$ & $\beta$ & $\gamma$ & $\nu$ & $\mu$ \\
\hline cloud droplets & 0.124 & $1 / 3$ & $3.75 \cdot 10^{5}$ & $2 / 3$ & 1 & 1 & 1 \\
raindrops & 0.124 & $1 / 3$ & 159.0 & 0.266 & $1 / 2$ & $-2 / 3$ & $1 / 3$ \\
cloud ice & 0.217 & 0.302 & 41.9 & 0.36 & $1 / 2$ & $1 / 3$ & 0 \\
snowflakes & 8.156 & 0.526 & 27.7 & 0.216 & $1 / 2$ & 1 & $1 / 3$ \\
graupel & 0.190 & 0.323 & 40.0 & 0.230 & $1 / 2$ & 1 & $1 / 3$ \\
\hline $\begin{array}{l}\text { The overview covers the setting of microphysical parameters for the size as velocity of hydrometeors, as } \\
\text { well as for particle mass distribution of hydrometeors under the assumption of generalised gamma } \\
\text { distribution. }\end{array}$
\end{tabular}

Table 2. Overview of the setting of model ensembles

\begin{tabular}{lrrrc}
\hline & \multicolumn{2}{c}{ setting } & \multicolumn{2}{c}{ scenario } \\
& $n_{C C N, \text { ini }}\left[\mathrm{kg}^{-1}\right]$ & $n_{c, \text { ini }}\left[\mathrm{kg}^{-1}\right]$ & $\mathrm{RF} 05$ & $\mathrm{RF} 20$ \\
\hline $\mathrm{ccn} 20$ & $20 \cdot 10^{6}$ & $18 \cdot 10^{6}$ & $\mathrm{x}$ & \\
$\mathrm{ccn} 40$ & $40 \cdot 10^{6}$ & $36 \cdot 10^{6}$ & $\mathrm{x}$ & \\
$\mathrm{ccn} 60$ & $60 \cdot 10^{6}$ & $50 \cdot 10^{6}$ & $\mathrm{x}$ & $\mathrm{x}$ \\
$\mathrm{ccn} 100$ & $100 \cdot 10^{6}$ & $50 \cdot 10^{6}$ & control & control \\
$\operatorname{ccn} 200$ & $200 \cdot 10^{6}$ & $50 \cdot 10^{6}$ & $\mathrm{x}$ & $\mathrm{x}$ \\
$\mathrm{ccn} 250$ & $250 \cdot 10^{6}$ & $50 \cdot 10^{6}$ & & $\mathrm{x}$ \\
\hline $\begin{array}{l}\text { Each x indicate a model runs with the prescribed initial concentration of CCN and } \\
\text { cloud droplets. }\end{array}$ & & & &
\end{tabular}

290 to introduce additional variability due to vertical changes in aerosol concentrations along the parcel trajectory, we set the initial $\mathrm{CCN}$ concentration constant per unit of mass with altitude, with the reference values at $850 \mathrm{hPa}$. The statistical distribution of aerosol concentration shown in figure 3 then motivates the setting of initial concentrations in the model ensembles prescribed in table 2. The maximum initial cloud droplet number concentration in the supersaturated areas ise set to $90 \%$ of CCN concentration in model runs with very low CCN concentrations (ccn20, ccn60), and to $50 \cdot 10^{6}\left[\mathrm{~kg}^{-1}\right]$ in other runs (including the control run ccn100). The sensitivity to the setting of the initial cloud droplet number is addressed in Appendix A1.

Due to the relatively short time-scales involved, the additional sources of CCN are neglected. This applies both to the surface flux of aerosols, as well as production of aerosols from the decay of non-nucleating aerosols. This topic is further addressed in the discussion 5. 


\subsection{Numerical Grid Configuration}

The choice of the model domain is motivated by the conditions in the Arctic troposphere. The horizontal extend of the model domain is $25.6 \mathrm{~km}$ in both directions. This is approximately four times more than the width of the convective rolls and other convective structures commonly observe in the Arctic troposphere (Muller et al., 1999). The vertical extent of the domain is set to $4900 \mathrm{~m}$, which allows us to capture both the AML as well as a large part of free atmosphere above it. The sponge layer is applied in the top $1 \mathrm{~km}$ of the computational domain to prevent the reflection from the rigid top boundary.

The horizontal resolution is set $50 \mathrm{~m}$ in both directions. With the focus on turbulence and microphysical processes, the vertical resolution is higher in the lower part of the model domain, starting with $25 \mathrm{~m}$ by the ground and decreasing with the altitude to $60 \mathrm{~m}$ by the domain top. The sensitivity of model results to this setup is addressed in Appendix A2; and for further details about the model setup, we refer to the statement on code and data availability.

\section{Results}

The results section is divided into two parts. Firstly, we provide a brief comparison of the modelled AML with the observations. Secondly, we address the question of the sensitivity of model results to the model setting. Then we focus on the impact of CCN concentrations on the evolution of the vertical structure of clouds. Finally, we investigate the impact of microphysical processes of the boundary layer turbulence. To gain a deeper insight into the cloud processes, we have extended model diagnostics by recording the mass tendencies and number tendencies in cloud processes. With an aim to keep these diagnostics consistent with model diagnostics for temperature tendencies, their values are first horizontally averaged over the whole model domain and then time averaged over the sampling time (900 s).

\subsection{Vertical Structure and Time Evolution}

The time development of the lower troposphere in RF05 depicted in Figure 5.a shows a nearly textbook example of a CAO. The initially shallow AML undergoes rapid deepening and warming due to increase in the surface temperature after 6 hour. Originally thin cloud later thickens due to adiabatic cooling with increasing altitude, as well as moisture transported from the surface. The comparison of vertical profiles of horizontally averaged potential temperature and humidity with the measurement from the dropsonde shows a reasonable agreement (see Figure 6.b). The height of the AML is well reproduced, as well as the strength of the inversion both in temperature and humidity. Slight negative biases exist in both the potential temperature and humidity. 


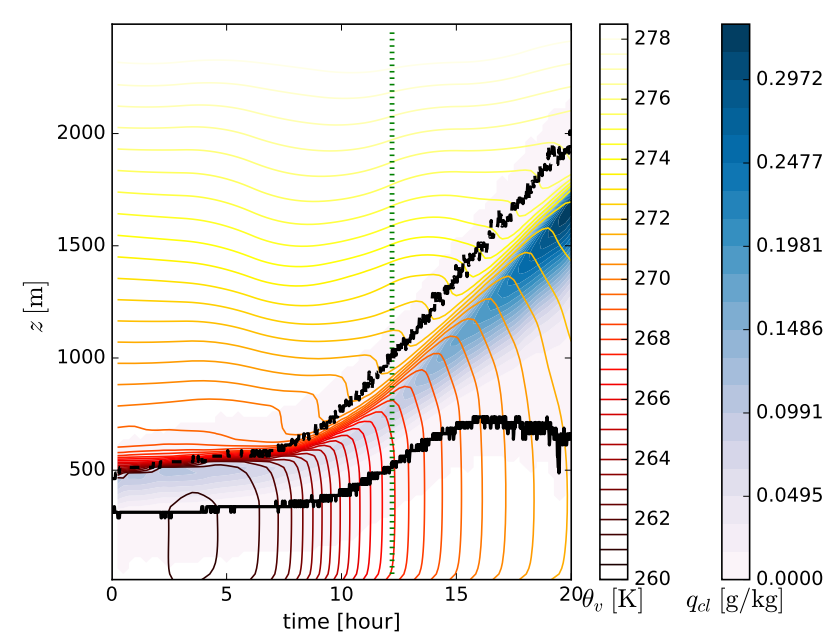

(a)

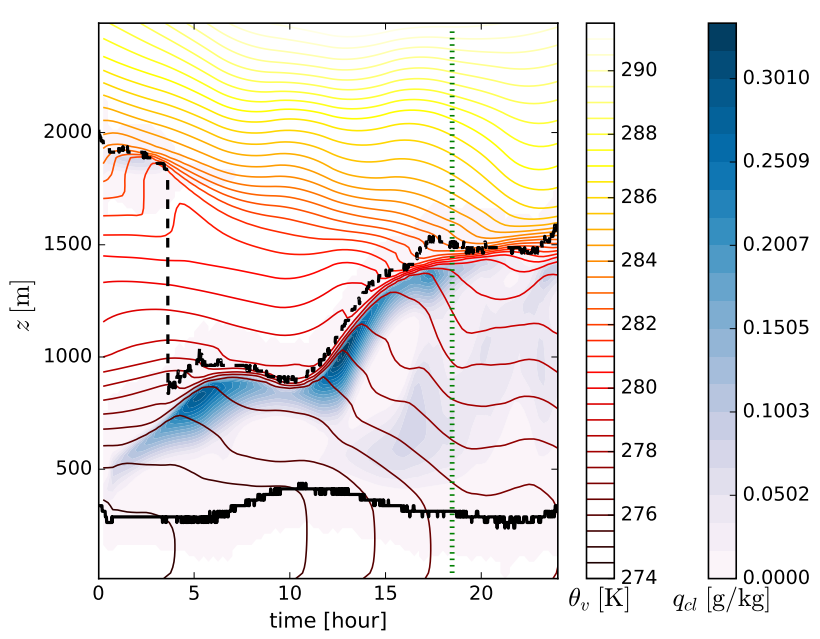

(b)

Figure 5. The evolution of the potential temperature and cloud liquid water content in the control runs of a) RF05 and b) RF20 scenarios. The black lines indicate cloud tops and cloud bottoms (with a threshold of $0.01 \mathrm{~g} \mathrm{~kg}^{-1}$ of total cloud water content), while the green line indicates the time of the dropsonde DS08.

The cloud layer significantly thickens from 10 hour onward. Over the whole time period, the liquid phase is dominating, with the ice phase contributing only 1-10\% of the total cloud water content (see Figure 8.a). However, the ice hydrometeors dominate the precipitations. At the time of dropsonde, most of the precipitation is in the form of larger ice crystals and snow. In the following hours, and increasing amount of graupel appears. This is mostly due to the thickening of the cloud (see Figure 7.a) and an increasing contribution of riming processes (see Figure 9.a). Although the precipitation in the bottom part of the clouds consists mostly of the snow, the mass of precipitating graupel and snow at the surface is approximately balanced.

The RF20 simulation shows an evolution of thick clouds over open water (see 5.b). The main cloud deck start at the altitude 300-600 m, and continue increasing in height with time. The secondary cloud layer is initially located at the altitude $2000 \mathrm{~m}$ and consist primary of ice. This secondary layer mostly evaporates and sublimates during the model spin-up, and disappears by 3 hours. For the rest of the simulation, the main cloud top is not obstructed by any additional clouds above it. With the increase in the surface temperature after 10 hour, the boundary layer enters the second warming and deepening phase. This continues until 16 hour, when the cloud top reach the altitude of a stronger temperature inversion. For the remaining 4 hours, further rising of cloud tops is inhibited, however the cloud layer continues warming due to entrainment and other processes. Similar to RF05, the profiles of horizontally averaged potential temperature and humidity at the time of the dropsonde. Similar to RF05 the thermodynamic vertical structure shows a reasonable agreement with the dropsonde measurements (see figure 6.b). 


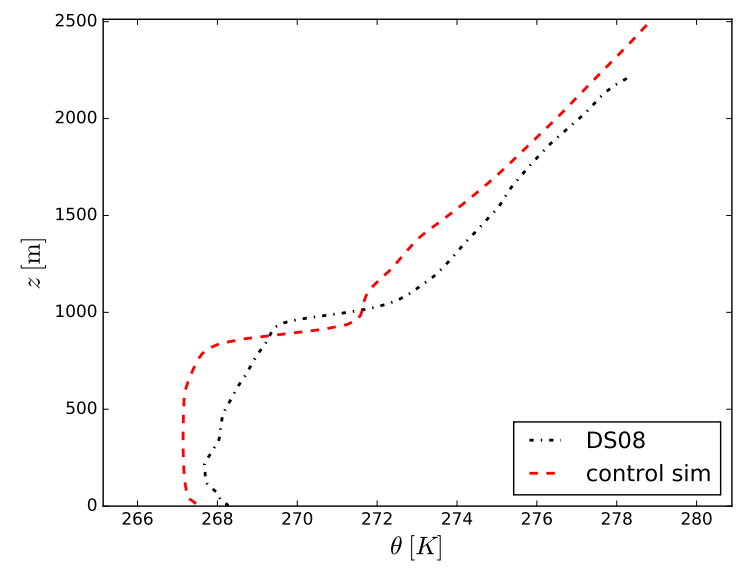

(a)

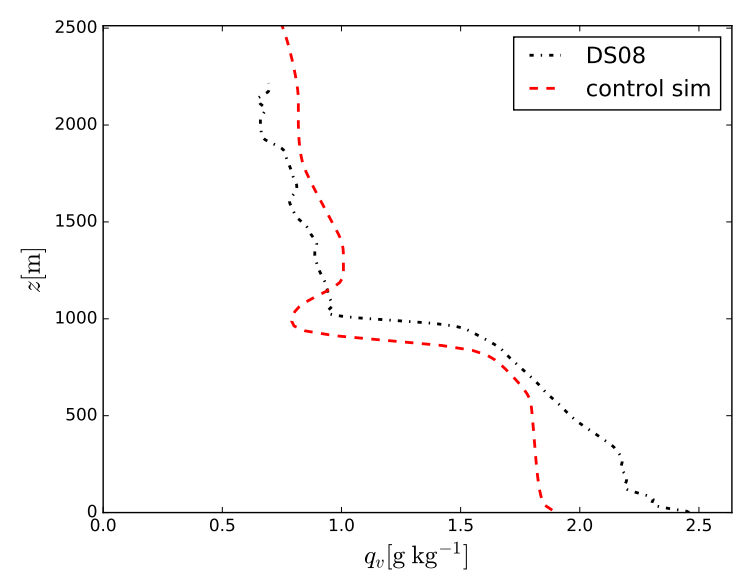

(c)

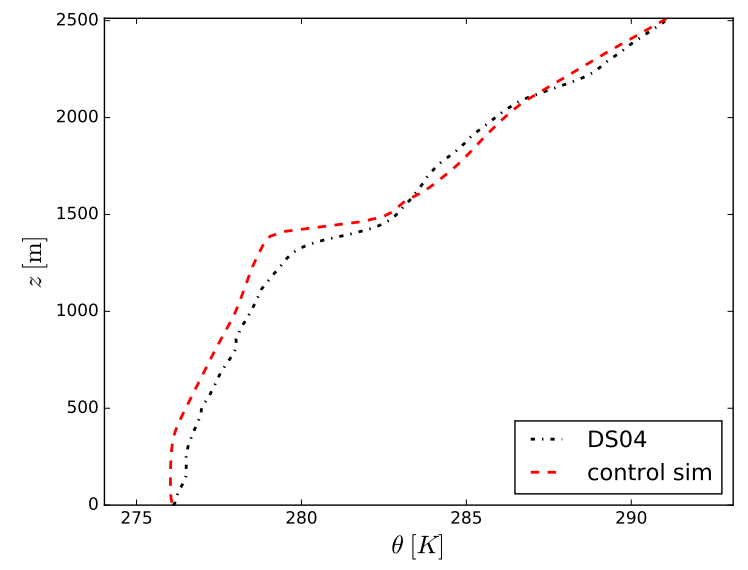

(b)

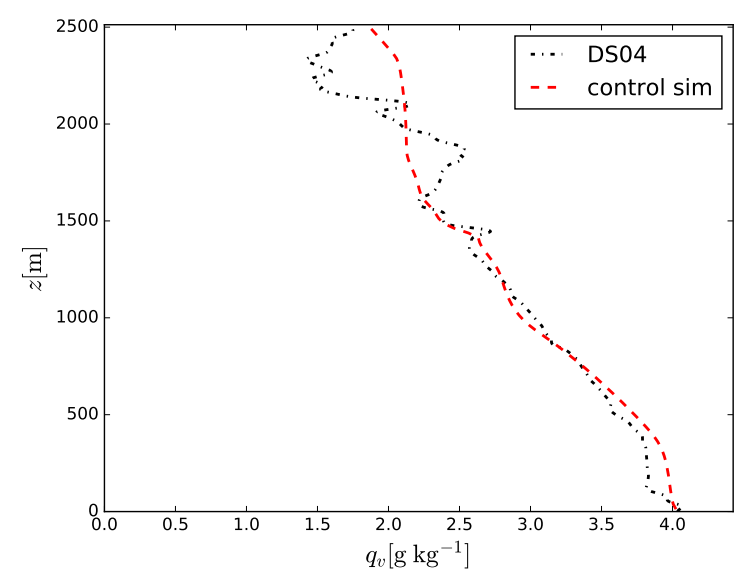

(d)

Figure 6. The comparison between the model with observations. The horizontally averaged profiles of potential temperature and specific humidity corresponding with the dropsonde launch are plotted against the vertical soundings from dropsondes. The comparison of the profiles from RF05 control run with the dropsonde DS08 is on the left side (a and c), while the comparison of RF20 control run and the dropsonde DS04 is on the right side ( $b$ and d).

Similarly to scenario RF05, clouds in RF20 are dominated by the liquid phase. Although liquid droplets are indicated over the whole depth of the cloud, most of the water content is located near the cloud top (see Figure 8.b. Meanwhile, the ice phase is more spread over the height of the cloud deck (see Figure 7.b). Figure 9.b shows that most of the ice precipitation forms by the aggregation of ice into snow, and then further grows by deposition. In the later stages after 15 hour, a secondary cloud deck consisting of liquid water develops in the middle part of the cloud layer (see again 5.b). At this stage, cloud ice crystals are mostly located in the upper half of the cloud layer. The aggregated snow then collects cloud droplets as it falls down. 


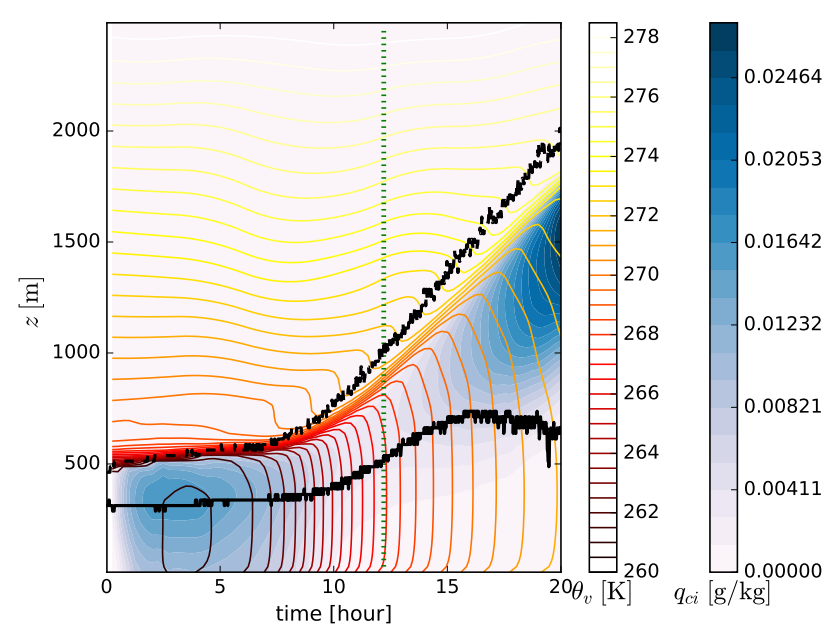

(a)

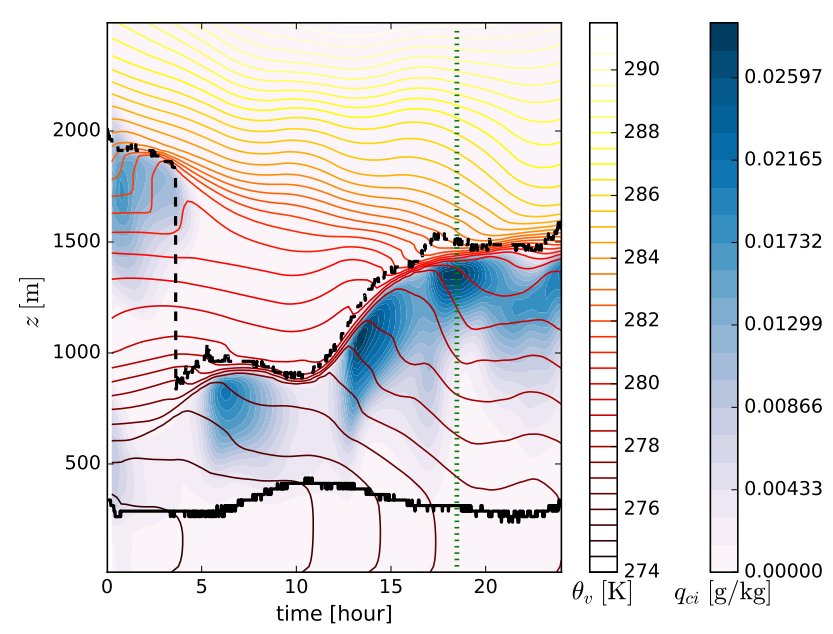

(b)

Figure 7. The evolution of ice cloud water content in the control runs of a) RF05 and b) RF20 scenario. The contourplots are created from horizontally averaged profiles sampled every $900 \mathrm{~s}$. The black lines indicate cloud tops and cloud bottoms (with a threshold of $0.01 \mathrm{~g} \mathrm{~kg}^{-1}$ of total cloud water content), while the green line indicates the time of the dropsonde DS04.

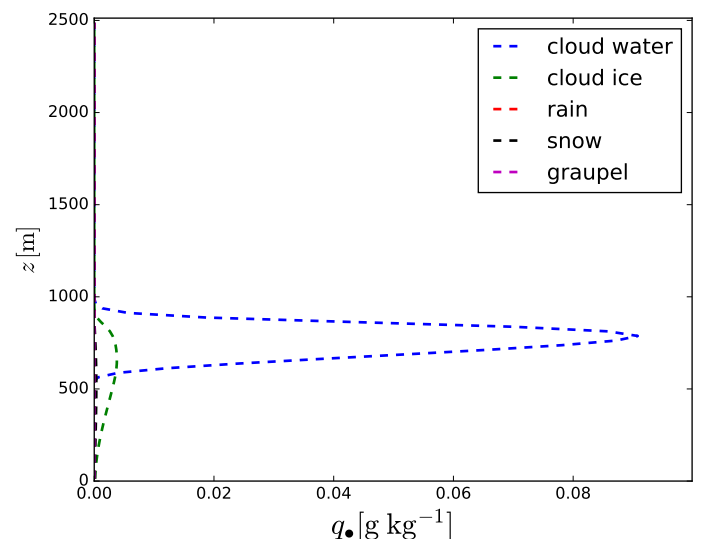

(a)

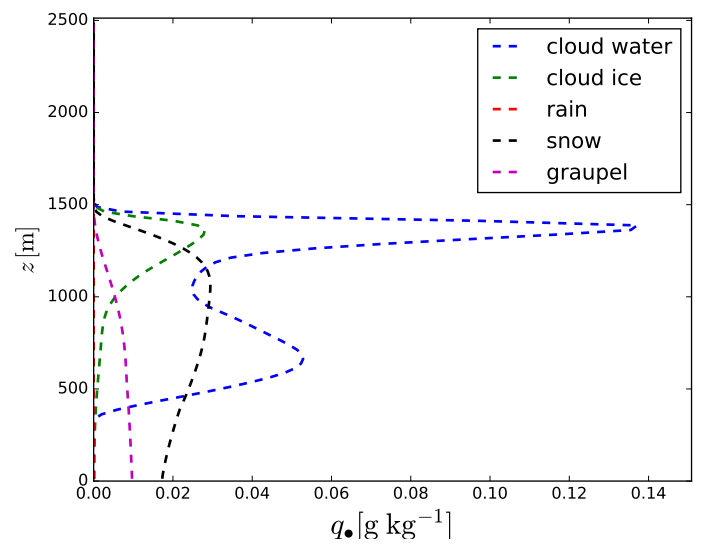

(b)

Figure 8. The specific mass content of hydrometeors at dropsonde launches in control runs of a) RF05 b) RF20. Lines show the horizontally averaged profiles. The value ranges on the $\mathrm{x}$-axis were adapted to better show differences between the hydrometoer species, thus they differ between $a$ and $b$.

\subsection{Impact of CCN Concentrations on Precipitation}

The simulations in the model ensemble of RF05 show relatively few differences during the first 12 hours. This is followed by an increasing amount of variability in the following hours. After the model spin-up, there are differences in the number of 


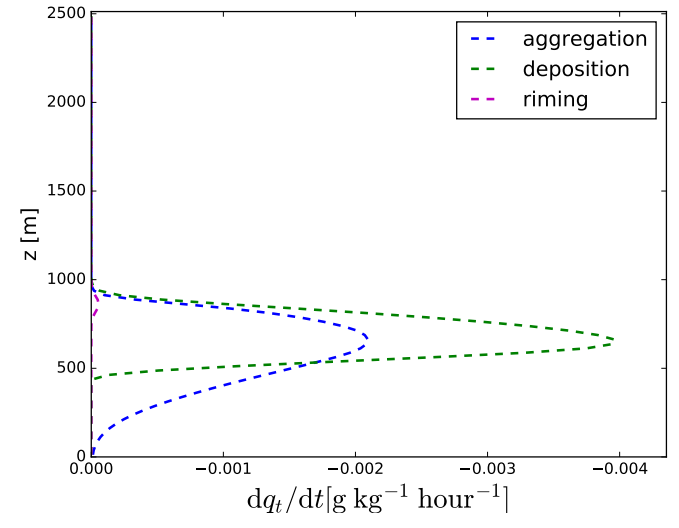

(a)

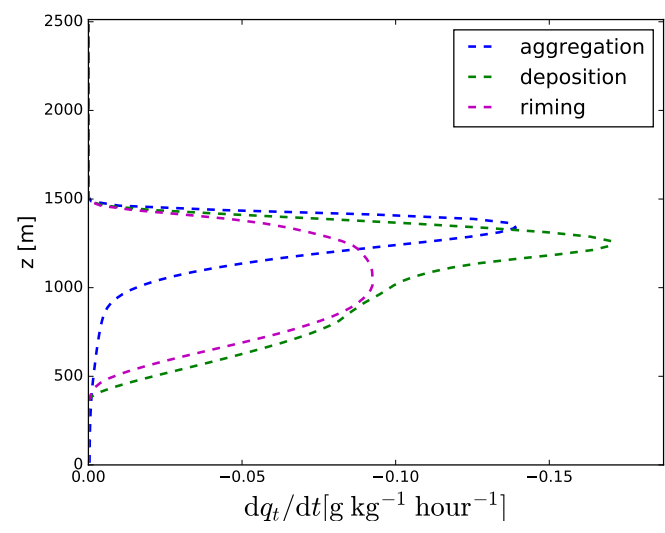

(b)

Figure 9. The specific mass content of hydrometeors and the relative contribution of processes to the formation of precipitation at dropsonde launches in control runs of a) RF05 b) RF20. Lines show tendencies that were first averaged horizontally, and then over the $900 \mathrm{~s}$ sampling window. The value ranges on were adapted to better show differences in the model ensembles, thus they differ between the left and the right column.

cloud droplets. These differences are however not proportional. Figure 10.a shows that in the control run and the ncc200 run, the droplet number concentration reaches $75-80 \%$ of the $\mathrm{CCN}$ number concentration, only half of the CCN in ncc20 and ncc40 appears to be activated. During this stage, there are virtually no differences in the liquid path (LWP) and ice water path (IWP).

With the thickening of the cloud after 10 hours, differences in the LWP between the model runs appear and continue growing (see Figure 11.a). This is primary caused by the differences in the precipitation rates (see Figure 11.e). However, there are relatively small differences in the IWP, mostly caused by the differences in the amount of snow (see Figure 11.c). The model ensemble exhibit relatively little spread in the amount of cloud ice. The aggregation of ice into snow is approximately balanced by the formation of more cloud ice. Although there are differences in LWP, all the model runs in the ensemble agree that most of the liquid droplets are in the upper part of the clouds. Furthermore, the model ensemble exhibit only slightly higher cloud tops in the runs with higher $\mathrm{CCN}$ concentrations (see Figure 12.a).

Meanwhile, model ensemble for RF20 scenario shows an early spread in LWP between runs (see Figure 11.b). Although the vertical structure of cloud layer remains similar as in the control run (Figure 8), there are slight differences in the height of the cloud top as well as in the amount of cloud water. Cloud tops here grow higher in the model runs with higher CCN concentrations. However the spread does not exceed $100 \mathrm{~m}$ (Figure 12.b). Figure 11.b further shows that differences in the LWP starts growing with the increase in LWP after 5 hour. These differences temporary disappear with the rapid growth of the clouds around 10-12 hour, but again appear soon after. While there are significant differences between the control run and runs cen60 and cen200, the differences between ncc200 and ncc250 mostly appear only after 18 hour. Similarly to to model 


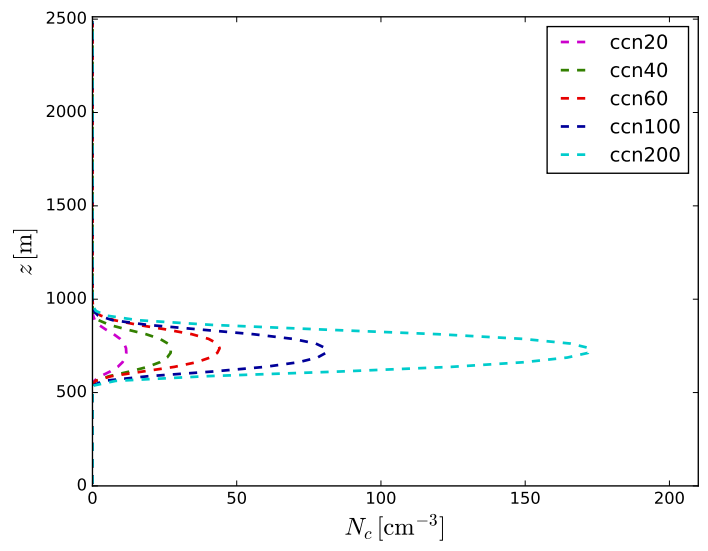

(a)

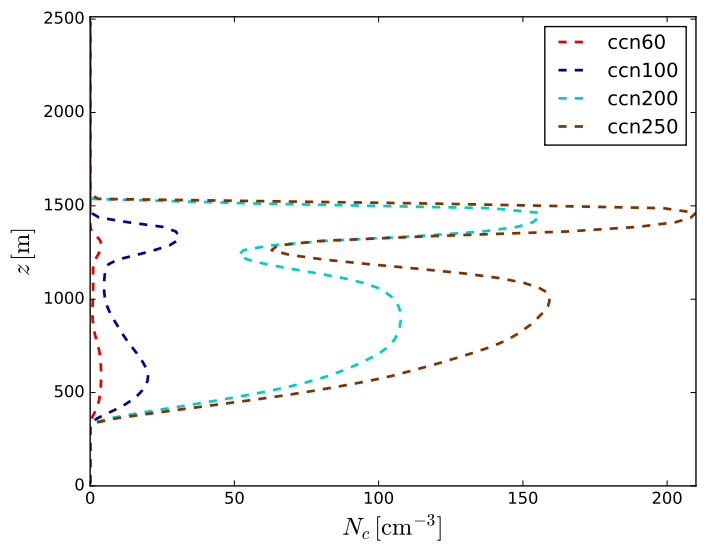

(b)

Figure 10. The spread in the cloud droplet number concentrations between the various model runs at the time of the dropsonde release in a) RF05 and b) RF20. Lines show horizontally averaged profiles.

ensemble RF05, runs with lower CCN concentrations generate more precipitation (see Figure 11.f).

Further evaluation of the tendencies in microphysical processes reveals significant variations between the later stages of model runs. Although ice hydrometeors still grow mostly by the deposition (see Figure 14), both model ensembles exhibit wide spread in riming of cloud droplets on ice hydrometeors (see Figure 14.b and d). In the RF05 runs, the riming tendencies are virtually negligible until 12 hours, it quickly grows afterwards. The riming rates in ncc 20 and ncc 40 runs are approximately twice as high as in the control run, while the riming rates in ncc200 run are by nearly order of magnitude lower. In RF05, the riming rates in ncc60 run is slightly higher than in the ncc100 control run. Meanwhile, riming rates in ncc200 and ncc250 are usually by an order of magnitude lower. Due to favourable temperature ranges within the cloud layer the ice multiplication by Hallett-Mossop process increases the number of ice crystals in all runs of the model ensemble. However, the tendency in ice secondary ice production is in runs ncc200 and ncc250 usually by an order of magnitude lower than in the control run and ncc60.

It is important to stress that the spread in the potential temperature of AML between the runs in neither RF05 nor RF20 exceed a half of $\mathrm{K}$ degree. Therefore, the differences in riming rates (Figure 14) are almost exclusively caused by different sizes of cloud droplets. Changes in the size of of hydrometeor due to riming and the number of secondary ice particles than further influence other other microphysical processes. Overall, the results indicate that although the riming processes account for less than half of the precipitation budget, they are responsible for most of the differences in LWP in the last 5 hours of models runs (see Figure 14). 


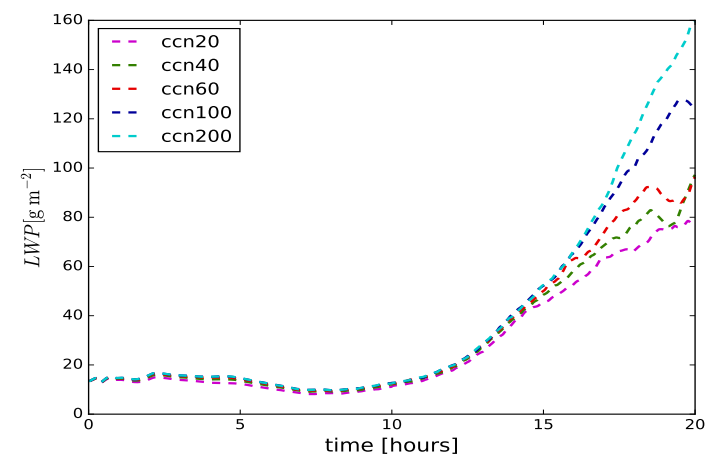

(a)

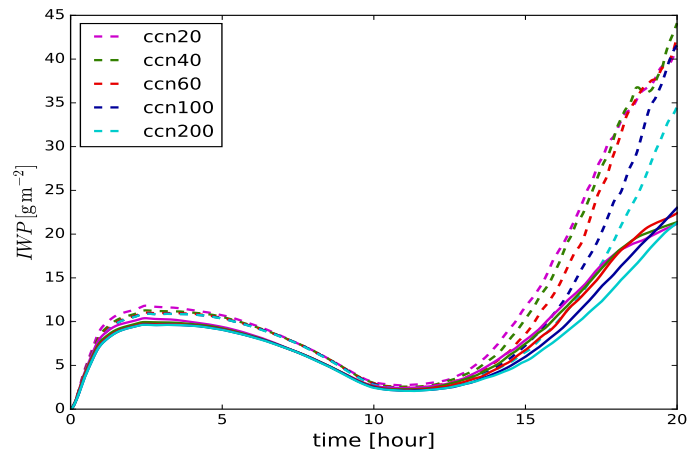

(c)

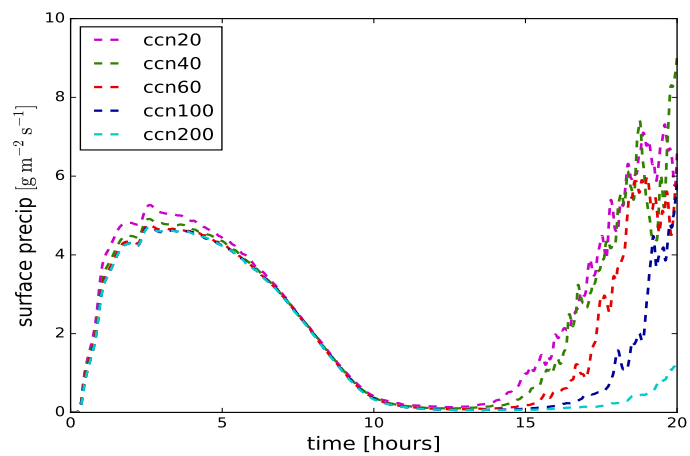

(e)

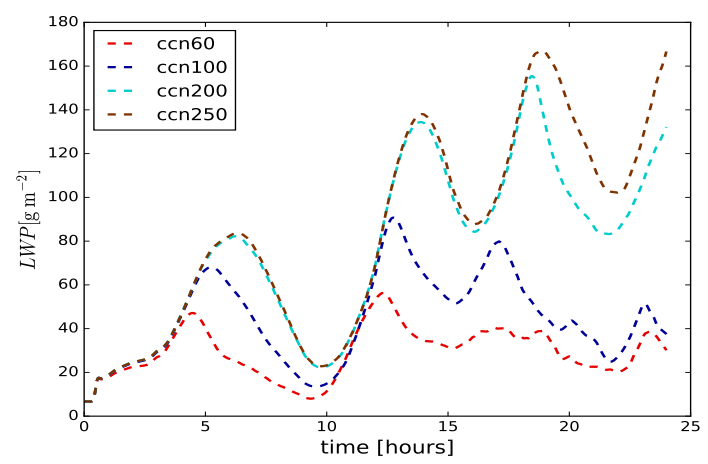

(b)

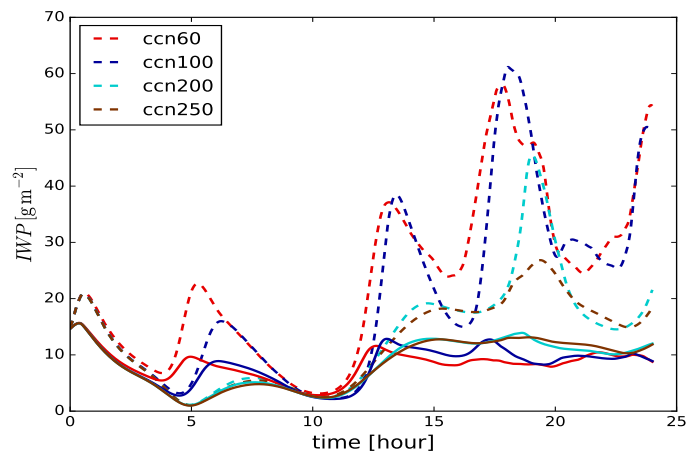

(d)

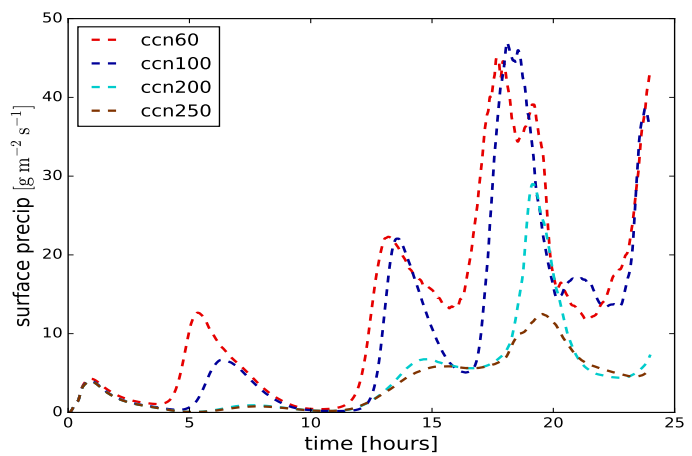

(f)

Figure 11. The LWP, IWP, and surface precipitation in model ensembles. The left column show R05 ensemble, while the right column show RF20 ensemble. The dashed lines in c) and d) indicate the total IWP, while full lines indicates the vertically integrated water path of cloud ice crystals only.

The model ensembles RF05 and RF20 further reveal spread in the water vapour. Figure 13 shows that model runs with lower CCN concentrations generally exhibit lower water vapour content in the cloud layer. In RF20 case, the effect of CCN is effect is strongest in the middle of the cloud layer, where is the majority of precipitation forming (see Figures 13.b and d). The 
figures also show strong differences near the cloud tops, mostly due to aforementioned differences in cloud top height. The differences in the precipitation (Figure 11) affect also the rest of the boundary layer. However the effect here can be adverse for higher CCN concentrations. This phenomenon is pronounced in the last five hours of the RF05:ncc200 run (see Figure 13.c). Lower precipitation leads to less sublimation from hydrometeors, which results in lower water vapour specific content in the bottom part of the AML. The effect of sublimation and evaporation-melting of ice precipitation in the subcloud layer slightly replenishes the water vapour there. Nevertheless, subcloud layer in RF20 case is still drier than in the model runs with higher CCN concentrations (see Figure 13.b).

\subsection{Impacts of CCN Concentrations on Turbulence}

Another important factor to consider is that there is that the impact of CCN concentrations do not only affect precipitation directly, but also involve secondary feedbacks: firstly, the decrease in $\mathrm{CCN}$; secondly, the modification of turbulence due to latent heat. The first phenomena is relatively straightforward - precipitation removes water droplets as well as the activated $\mathrm{CCN}$, while entrainment of the CCN-richer air from the free troposphere replenishes some of the losses. However, the second phenomenon is less straightforward, and requires further investigation.

Figures 15.a and $\mathrm{b}$ show the vertical structure of TKE in both cases, illustrating that turbulence in the CAO case RF05 a lot more intense. This is due to the strong buoyancy forcing at the surface, resulting from cold air moving over warm sea water. Figure 12.d then shows that model runs with higher CCN concentrations exhibit higher entrainment velocity during the deepening of the cloud layer in RF20 model ensemble. This is also reflected in the faster the higher cloud tops in in model runs with higher CCN (see figure 12.b). On the other hand, higher CCN concentrations in RF05 result in only minor increase in the entrainment velocities. Near cloud top, TKE is smaller with lower CCN concentrations in both cases (see Figure 15). RF05 ensemble generally show less turbulent kinetic energy (TKE) in runs with lower CCN. Figure 15 gives more information about this behaviour, showing that TKE near cloud top is smaller with lower CCN in both model ensembles. This is generally in line with the expectation that clouds with less cloud water exhibit lower intensity of processes that drive turbulence. The situation is more complicated for the cloud layer interior, which in RF20 cases shows a reduction of TKE with higher CCN concentrations (see Figures 15.b and d). Figure 15.b shows that the TKE in ncc60 is after 5 hour generally higher than in the control run. This is followed by further increase after 15 hour. Runs with higher CCN concentration exhibit after 15 hour generally less turbulence in the cloud layer than the control runs (see figure 15.d).

The explanation of this phenomena requires further insight into the microphysical processes in the lower part of the cloud deck. The growth of the ice phase leads to the release of latent heat, warming the surrounding air. Furthermore, there are also understaturated columns where the descending ice hydrometeors begin to sublimate. The latent heat consumption during this process then further cools down the surrounding air. Higher precipitation rate then could lead to higher TKE production. The evaluation of model tendencies support this. Figure 16a shows that there is number of altitudes where a higher sublimation 
https://doi.org/10.5194/acp-2019-637

Preprint. Discussion started: 17 July 2019

(c) Author(s) 2019. CC BY 4.0 License.

(c) (i)

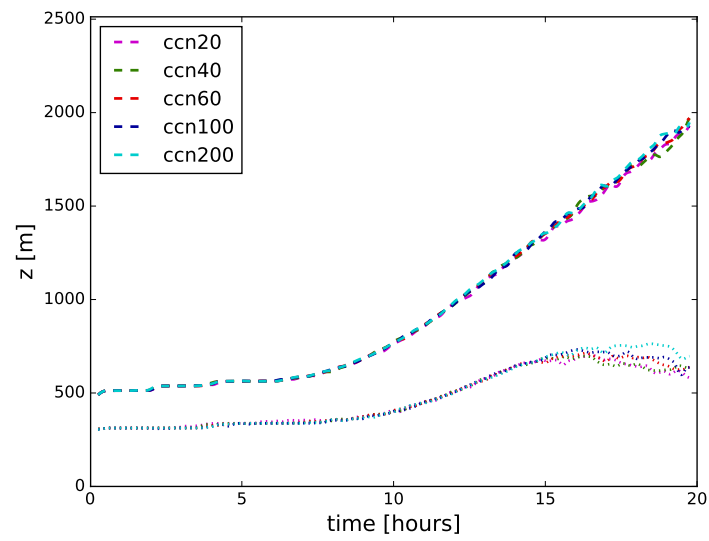

(a)

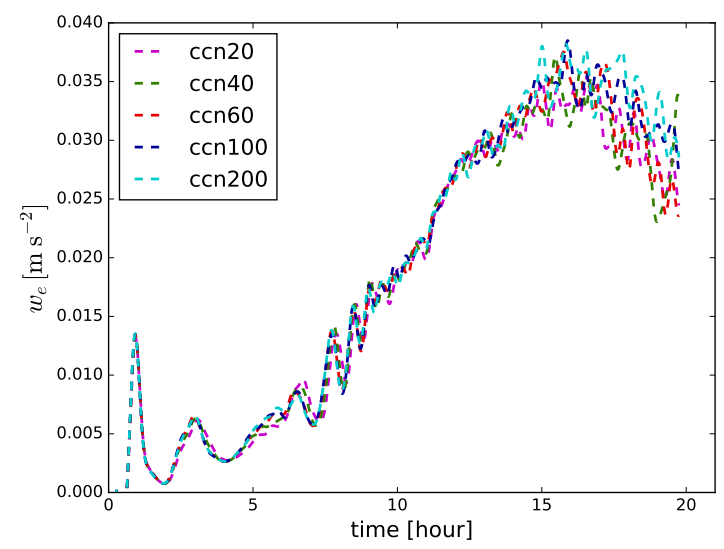

(c)

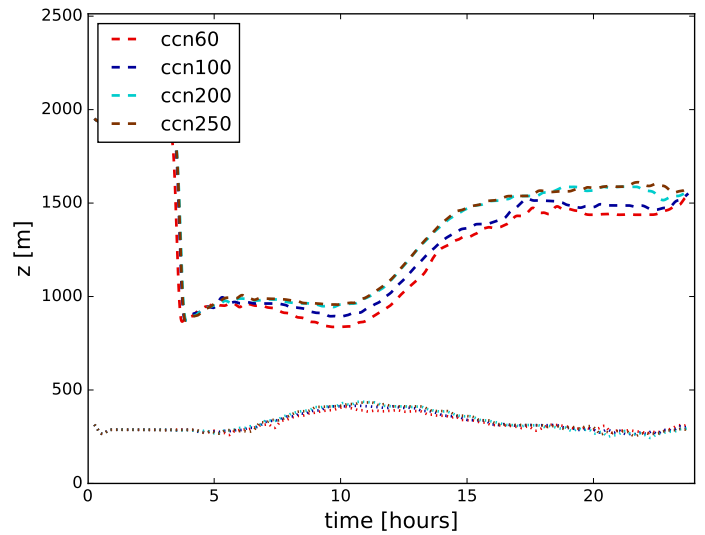

(b)

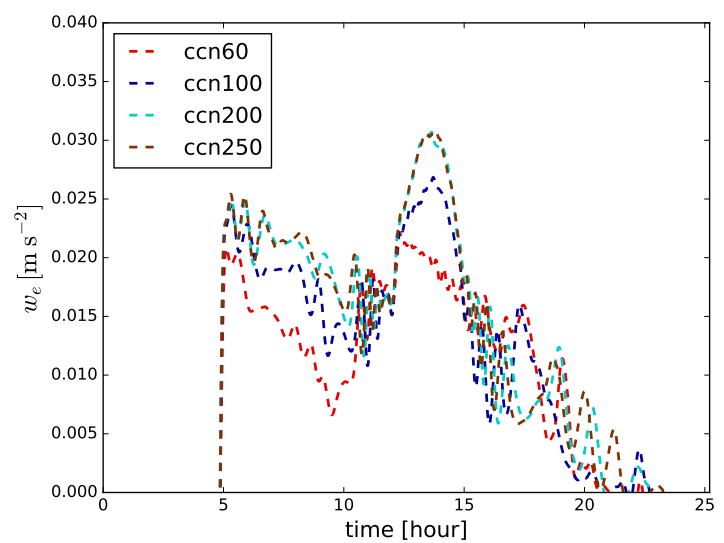

(d)

Figure 12. The differences in the altitude of cloud tops and cloud bottoms (a,b), and the entrainment velocity (c,d) within model ensembles. The left column depicts RF05 ensemble, while the right column depicts RF20 ensemble. The timeseries were smoothed with $1800 \mathrm{~s}$ moving window to remove excessive oscillations. The invalid values of model diagnostic in RF20 are not shown - in the first five hour, ther diagnostic is rendered invalid by dissipating cloud layer above, and it the last three hours, there were occasionally negative values.

rates coincide with a positive difference in TKE. Similarly, the runs with higher CCN concentrations exhibit generally less precipitation that can sublimate and enhance the TKE (see figure 16.b,c). Nevertheless, no such effect was found in RF05 model ensemble. 

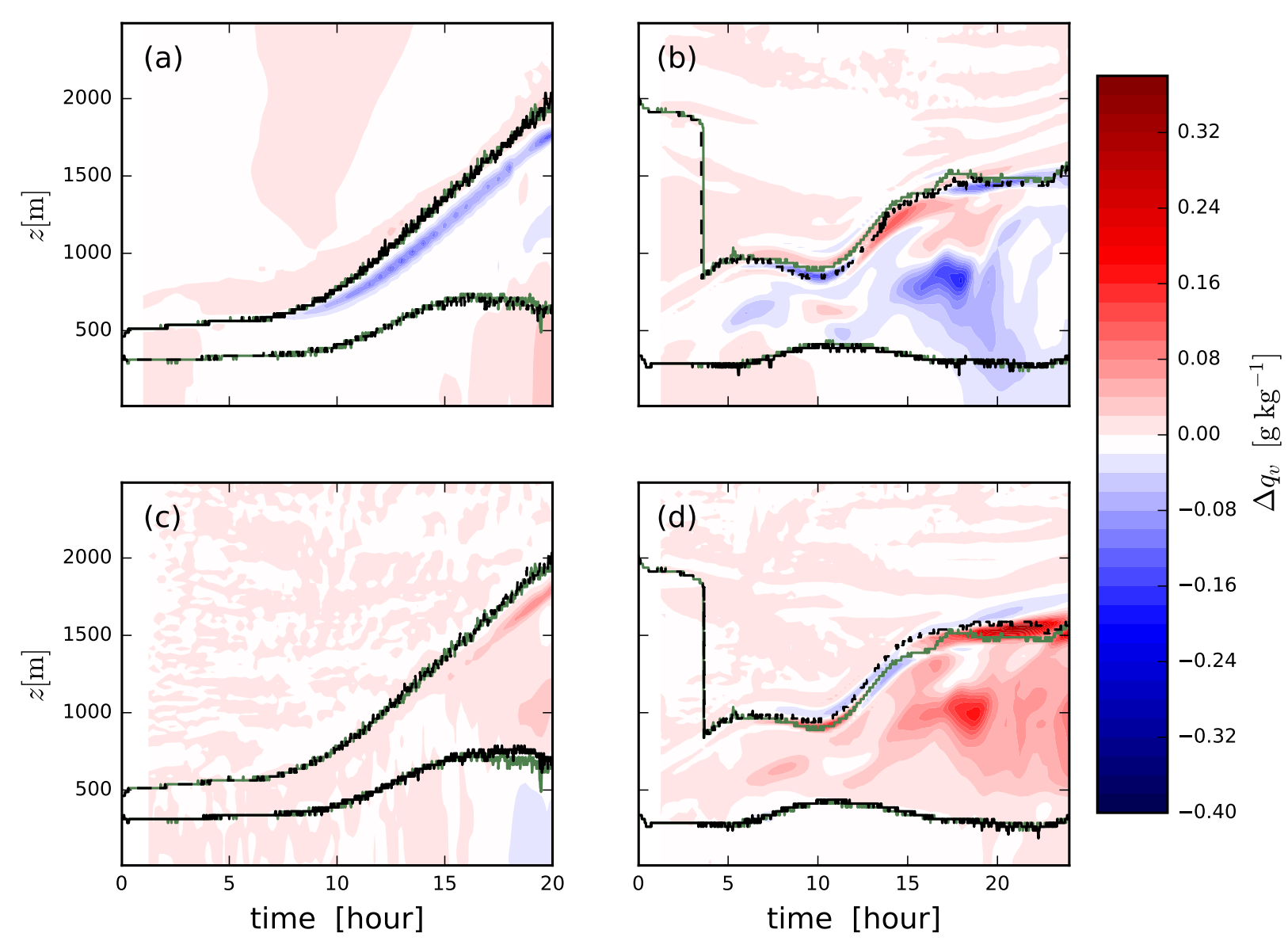

Figure 13. The differences in the vertical averages of water vapour between the models in the ensemble and the control runs (ncc100). The left column for RF05, while the right column for RF20. a) and b) show the TKE in control runs, c) and d) show the difference between ncc60 and control in RF05 and RF20, e) and f) show differences between ncc200 and control in RF05 and RF20. Black lines mark the altitude of cloud tops and cloud bottoms, while dark green lines mark the altitude of cloud tops and bottoms in the control run (all with a threshold of $\left.0.01 \mathrm{~g} \mathrm{~kg}^{-1}\right)$. 


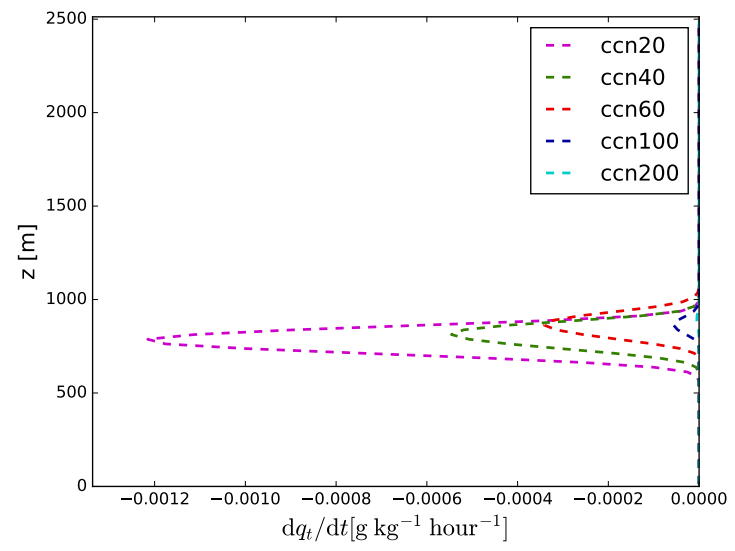

(a)

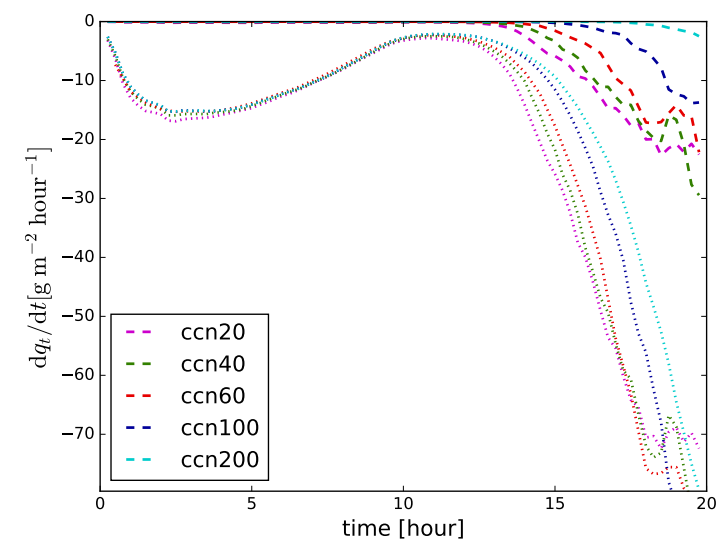

(c)

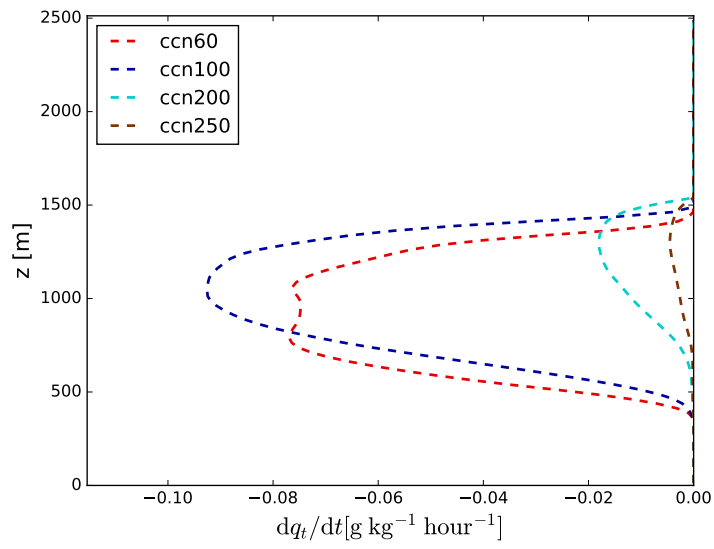

(b)

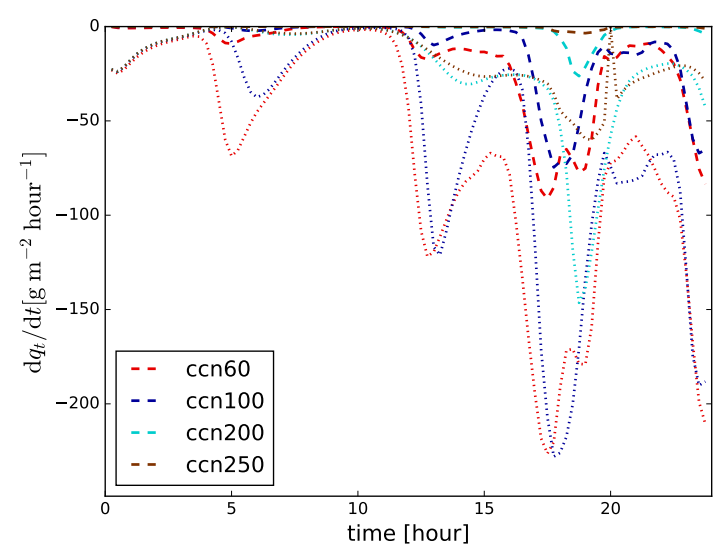

(d)

Figure 14. Riming tendencies in model ensembles, a)b) shows the horizontally averaged tendencies in RF05 and RF20, while c) and d) shows the time development of vertically integrated tendency. The dotted lines in c) and d) than indicate vertically integrated tendency in total precipitation production. The value ranges on the $\mathrm{x}$-axis were adapted to better show differences in the model ensembles, thus they differ between the left and right column.

\section{Discussion}

\subsection{Understanding CCN Impacts}

The main goal of this study was to gain a better insight into the role of $\mathrm{CCN}$ concentrations in the evolution of low-level clouds and turbulence in the Arctic. LES runs follow the evolution of low-level mixed-phase clouds over open water. Both liquid and ice phase are present, with the former being dominant. Although the ice water path is only a small fraction of the total cloud water path, ice particles are mostly responsible for the removal of water from the cloud layer. In agreement with Pithan et al. 

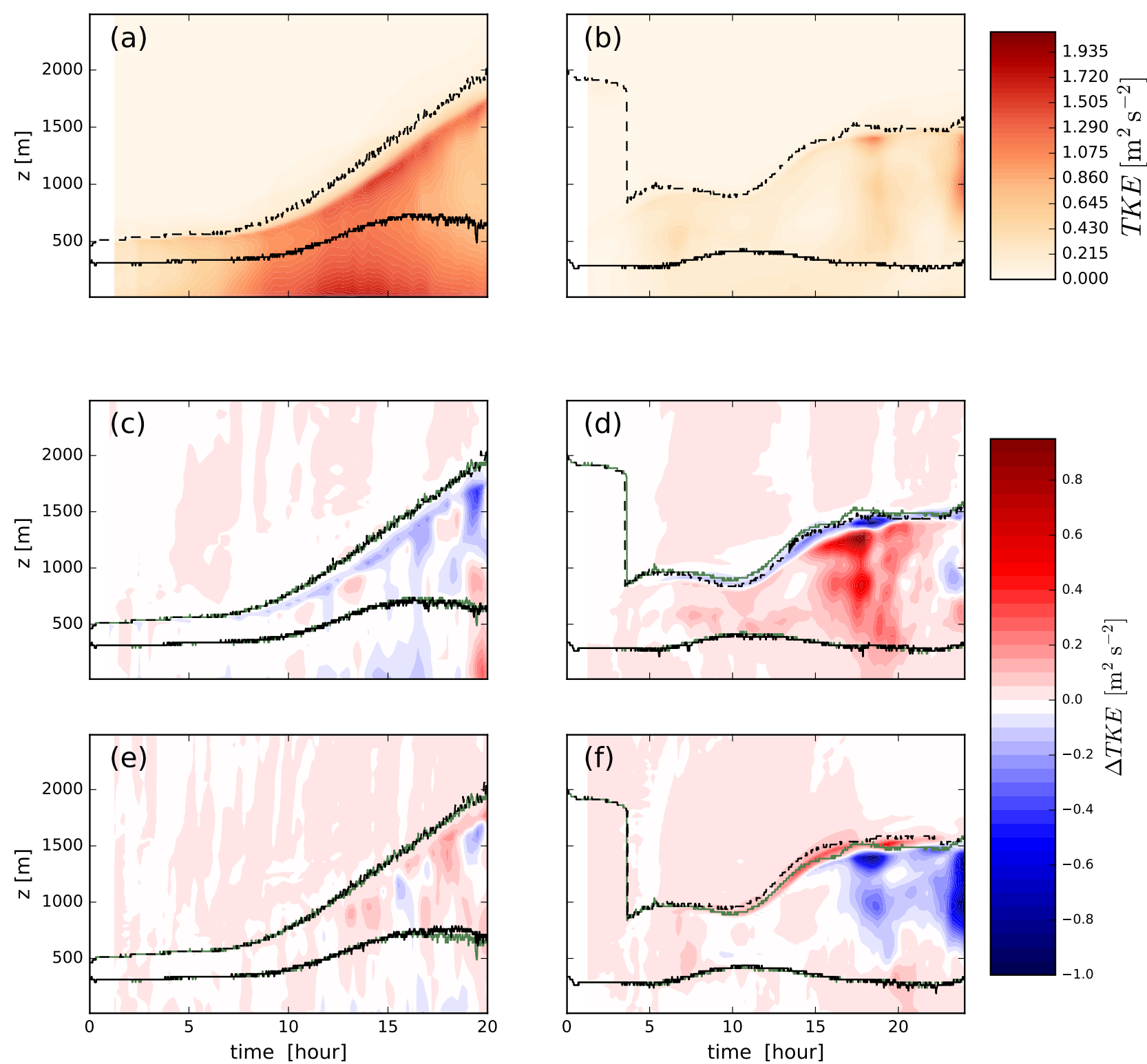

Figure 15. The differences in the vertical averages of TKE between the models in the ensemble and the control runs (ncc100). The left column in depicts runs from RF05, while the right column depicts RF20 runs, a) and b) show the difference between ncc60 and control in RF05 and RF20, c) and d) show differences between ncc200 and control in RF05 and RF20. Black lines mark the altitude of cloud tops and cloud bottoms, while dark green lines mark the altitude of cloud tops and bottoms in the control run (all with a threshold of $0.01 \mathrm{~g} \mathrm{~kg}^{-1}$ ). 


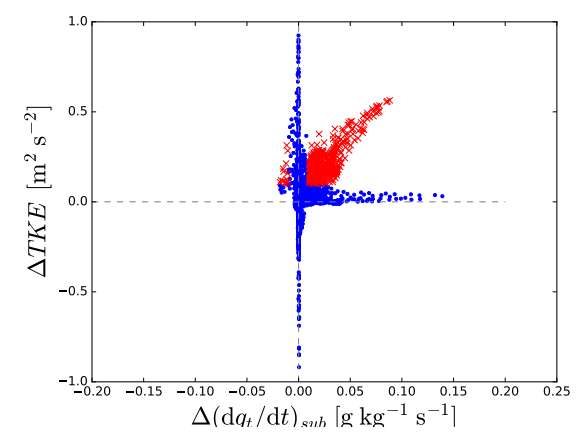

(a)

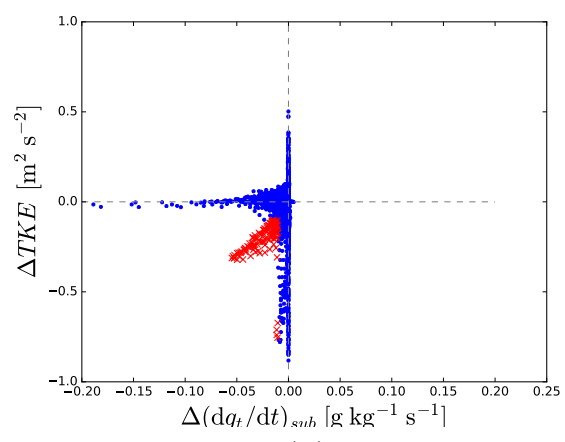

(b)

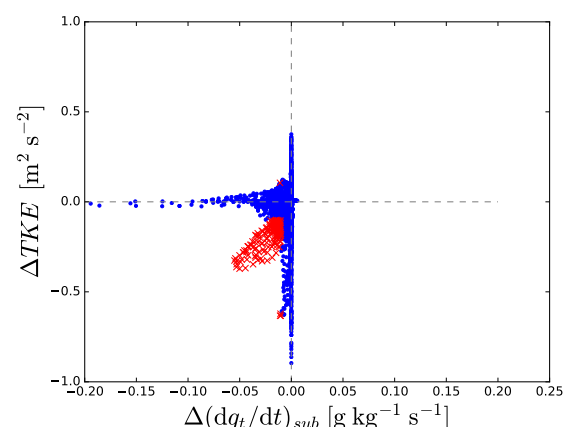

(c)

Figure 16. The incidence scatter plot of TKE differences with the differences in sublimation rates in RF20: a) ncc20, b) ncc200, c) ncc250. On the $\mathrm{y}$-axis are differences in the horizontally averaged TKE between the run and the control run (ccn100), while on the $\mathrm{x}$-axis are differences in horizontally averaged sublimation rate in the model. Each blue dot corresponds to sampling at one time at one altitude. Red cross markers then highlight points where the absolute difference in TKE exceeded threshold $0.1 \mathrm{~m}^{2} \mathrm{~s}^{-2}$ and the difference in sublimation rates exceeded $0.01 \mathrm{~g} \mathrm{~m}^{-2} \mathrm{~s}^{-1}$

(2018) and Tan and Storelvmo (2019), we find that ice cloud particles are mostly responsible for the formation of precipitation. Ice particles are mostly growing by the deposition, since saturated vapour pressure over ice surface is lower than the saturated pressure over water.

However, the mass of precipitating particles can also grow due to riming of cloud droplets. This is particularly relevant when the cloud depth is increasing. The increased depth of the cloud increases the number of collisions between ice particles and cloud droplets, leading to higher riming rates. Deeper clouds thus allow the development of rimed snowflakes (as well as graupel), which is in agreement with the observational evidence from polar climates (Young et al., 2016). The analysis of two model ensembles indicate a clear impact of modified CCN concentrations on the precipitating processes, as well as the turbulence in the boundary layer. We are going to focus on this topic in the following paragraphs.

The CCN modifies the number of droplets, resulting into changes in ice formation. Under low CCN concentrations, precipitation tend to form easily and remove the water from the cloud layer (Mauritsen et al., 2011). Similarly to studies of Lance et al. (2011) and Zamora et al. (2017), we find that a higher CCN concentration leads to a higher number of cloud droplets, and subsequently suppressed ice formation and increased LWP. Lower CCN concentrations generally lead to faster formation of solid precipitation, resulting into more water being removed from clouds. Still, there is also a negative feedback loop, as a removal of cloud water leads to lower amount of water available for precipitation. Overall, cloud water path differs up to the $30 \%$ of total cloud water content. At the same time, the differences in the cloud height are relatively minor. 
The explanation of these phenomena is relatively clear, but not straightforward. The composition of mixed-phased clouds is modified by the combination of a number of microphysical processes. The rate of these process is dependent on thermodynamic properties of the air as well as the sizes and concentration of particles involved. A larger size of a hydrometeor implies a larger effective diameter as well as higher terminal velocity. The combination of these two increases the probability of collision with other hydrometeors, both the hydrometeors of the same type, as well as hydrometeors of other species. Therefore, changes in the size distribution of one hydrometeor species often lead to feedbacks in the distribution of other hydrometeor species. For example in the case of cloud droplets, distributing the same amount of cloud liquid water over a higher number of small droplets leads to the suppression of liquid precipitation (Seifert et al., 2015).

That said, the important phenomenon is the combined effect of mixed-phase processes. A particular case here is riming. When cloud droplets coexist with ice particles, the increase in the size distribution of droplets results into higher collision rates. This leads not only to the removal of said cloud droplets, but also faster increase of the mass of said ice particles. This bears two important implications. Firstly, the ice particles grow in size and therefore descend faster. Secondly, in the favourable temperature regime for Hallett-Mossop process (here in RF20), this also results into a stronger secondary ice production. The higher number of newly formed small ice particles is then more likely to collide with remaining cloud droplets. that ice deposition and sublimation can affect the buoyancy in the cloud and subcloud layer. We find that in scenarios with deeper clouds and a relatively weak surface heating, the increased sublimation of precipitating hydrometeors coincide with an increase in TKE. However, this effect is limited. In a case of shallower clouds and stronger surface forcing, the effect of sublimation is unlikely to lead to increase in TKE. We conclude that in the presence of thicker clouds, lower CCN concentration can lead to an enhancement of boundary layer turbulence through the effect of increase sublimation of precipitation.

\subsection{Limitations}

The semi-idealised model constrained by observations presents a complex representation of developing weather situation. Nevertheless, numerical simulations in general always introduce some degree of simplification of the underlying physical problem. Simplifications are generally enforced both by the description of the physical system as well as by computational constrains. In the following paragraphs, we will discuss the main simplifications that were introduced in our model study.

Perhaps the main simplification of our study was applying a simple parameterization of Reisner et al. (1998) for ice nucleation. Although there are number of more advanced parameterizations of ice nucleation, they often require additional parameters (Fan et al., 2017). This is particularly relevant in case when we do not have a clear information about the chemical composition of aerosol (Kanji et al., 2017) (Mei et al., 2019) or the size distribution of ice particles (Ovchinnikov et al., 2014). Furthermore, the exact number of ice particles is generally not too important (Khain et al., 2015) for model dynamics. Then 
there are also certain benefits of applying a simple scheme - it is consistent with the rest of the Seifert \& Beheng parameterization (Seifert and Beheng, 2006a), and was previously used in a number of intercomparison studies (de Roode et al., 2019).

Although it would be also an interesting research question to evaluate the impact of INP concentrations in the Arctic clouds (Prenni et al., 2007), this remained outside of the scope of our study. There is a wide range in concentrations of INP (Fan et al., 2017), and a high temporal variability (Hartmann et al., 2019). But there are also a number of practical issues. Firstly, the simulations constrained with the measurements of INP generally tend to under-predict the observed amount of ice in the Arctic troposphere (Costa et al., 2017) (Fridlind and Ackerman., 2018) and remove INPs in case of low initial concentrations (Fu and Xue, 2019) that are common in the Arctic air. Secondly, the identity of the factor that controls activation of INP is still mostly unknown (Kanji et al., 2017) (Willis et al., 2018), or is too sensitive to be easily estimated (Fan, 2013).

Furthermore, most of the ice in Arctic low levels clouds is not a pristine primary ice, but rather a mix that includes not only frozen drops and primary ice crystals, but also broken ice pieces (Rangno and Hobbs, 2001). The origin of a wide range of particles is often related to the boundary layer circulation (Tjernström et al., 2019), although the number of particles is often higher in non-coupled clouds. The underestimation in the concentration of ice particles could be often caused by the misrepresentation of ice multiplication processes (Fridlind and Ackerman., 2018). Nevertheless, although the number of ice particles plays an important role in the AML development (Young et al., 2018), the impact of INP is not expected to be too strong (Lance et al., 2011), and generally not stronger than impact of CCN (Gryspeerdt et al., 2018).

\section{Summary and Conclusions}

This modelling study has explored the impact of CCN concentration on the development of low-level mixed-phase clouds during the spring season in the Arctic. The main focus is on the thermodynamic and turbulent properties of developing convective clouds. The main novelty of our study lies in the the treatment of $\mathrm{CCN}$ concentration as a prognostic variable and accounting for the consumption of CCN in some of the cloud processes. Semi-idealised LES scenarios are based on observed cold-air outbreak cases during the ACLOUD field campaign, and constrained with the date from airborne observations.

Our main findings are:

- While the ice phase forms just a fraction of the mass of cloud water, it is responsible for most of the precipitation. Increasing the $\mathrm{CCN}$ concentrations leads to the suppression of ice formation, and thus decreased precipitation. This is in line with other LES and observational studies. 
- While lower CCN concentrations lead to increased precipitation, the main process responsible for the faster removal of water is riming. Although the ice particles grow mostly by deposition, riming of cloud droplets accounts for most of the differences between the the runs with different $\mathrm{CCN}$ concentrations.

- Although the lower CCN concentrations lead to lower liquid water path, it causes just very minor differences in the vertically integrated mass of simple cloud ice. The explanation of two-fold: firstly, increased aggregation of ice crystal, and secondly, increased collection of ice crystal by rimed snow particles.

- Differences in CCN concentrations can indirectly affect boundary layer turbulence. Turbulence (TKE) near cloud top increases with $\mathrm{CCN}$ in both cases, boosting top-entrainment. However, there canbe additional effects in the cloud layer interior. In the cases of a deeper cloud layer with a sufficient amount of water, lower CCN results into an increased turbulence in the boundary layer. This is due to increased amount of sublimation of ice hydrometeors that affects the buoyancy.

Overall, this study indicates an importance of the effect of CCN concentrations on the structure of low-level mixed-phase Arctic clouds and turbulence. The evolution of the cloudy Arctic mixed-layer can not be fully understood without the knowledge of the aerosols properties. Considering the high variability in Arctic air masses, the impact of CCN concentrations on the liquid water path and snow precipitation should be taken into account in parameterizing the radiative properties of said clouds for the purpose of NWP forecast and climate models. This is becoming increasingly important with the changes in the sea-ice cover in the warming Arctic. . Regarding the future observational studies in the Arctic, we encourage simultaneous measurements of microphysical and turbulent properties of the air. It is expected that this can help us to gain a deeper insight into the enhancement of turbulence by heat release due to precipitation. We are looking forward the upcoming Multidisciplinary drifting Observatory for the Study of Arctic Climate (MOSAiC) field campaign, which will include extensive amount of collocated measurements of the properties of Arctic air.

Code and data availability. The current version of DALES (dales-master 4.1) is available on: https://github.com/dalesteam/dales/releases/tag/v4.1, The aerosol dataset is part of the data publication on PANGEA: https://doi.org/10.1594/PANGAEA.900403, The configuration files for model scenarios, our code update, as well as the main model outputs are available at https://doi.org/10.5281/zenodo.3271773 (last update July 2019).

\section{Appendix A: Sensitivity Study}

555 There is a number of model parameters that can theoretically alter the results. Firstly, we have investigated the sensitivity to $n_{c, \text { ini }}$, the initial cloud droplet number concentration. The sensitivity runs were performed for both scenarios. Secondly, the sensitivity of the model runs to the setting of grid parameters was assessed by means of an additional set of model runs for the scenario RF05. In the following paragraphs, we provide a brief description of the sensitivity tests. For further results of the 
sensitivity tests, we refer to appendix.

\section{A1 Sensitivity to Initial Cloud Droplet Number}

The sensitivity to the initial cloud droplet number concentration was investigated using a set of model runs where the CCN concentration was the same as in the control run. During the cloud initialisation, the cloud droplet number in the saturated areas was set to the maximum values a) $18 \cdot 10^{6} \mathrm{~kg}^{-3}$, b) $80 \cdot 10^{6} \mathrm{~kg}^{-3}$. The test revealed that although the a lower cloud droplet number concentration leads to faster formation of precipitation in the first few model steps, this effect is short-lived. The differences between the model runs have disappeared already within the model spin-up in the first hour of model run. Therefore, in the initial cloud droplet number concentration is not a relevant parameter in this model study.

The test revealed that the impact of the initial cloud droplet number concentration is very short-lived. Although the a lower cloud droplet number concentration leads to faster formation of precipitation in the first few model steps, this effect is very short-lived. In the convective boundary layer, the differences between the model runs have disappeared already within the model spin-up in the first hour of model run. There are no significant differences in the first 18 hours of model runs (see figure A1). The spread between the model runs that appear later are related to random differences in the runs. Overall, in the initial cloud droplet number concentration is not considered a relevant parameter in this model study.

\section{A2 Sensitivity to Domain size and Resolution}

The sensitivity to the domain setting was tested on a set of model runs where one of the properties was modified. While the boundary layer in R05 scenario is shallower than in RF20 and clouds are generally thinner, it was expected that this scenario would possibly exhibit more sensitivity to the grid resolution. The sensitivity set included both the model runs with changes in vertical or horizontal resolution, as well as the model domain with changes in the horizontal extend. The main results are summarised in the table A1.

Overall, the analysis of the sensitivity to model resolution indicated differences in TKE and precipitation. The results suggest that coarser resolution leads to oscillations in the entrainment velocity, as well as higher precipitation. The coarser horizontal resolution generally lead to decrease in TKE and lower water path. The run with final horizontal resolution produced more snow within clouds, however there were no significant changes in the LWP nor IWP. Generally speaking, further improvements in the domain size or vertical resolutions lead to increase in the computational expenses without a clear benefit on model results.

Author contributions. SM provided the aerosols field measurements, as well as the guidelines on the treatment of aerosols. RN designed the model framework and prepared the model forcing files. JC developed the model extension for the interaction of aerosols and mixed- 


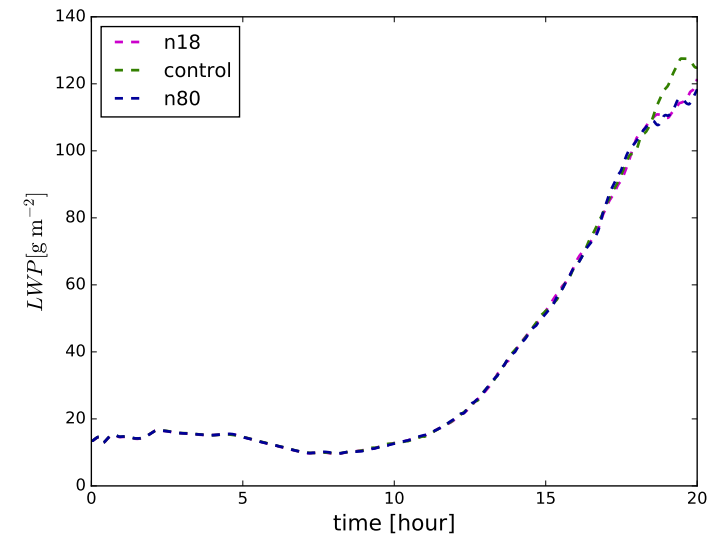

(a)

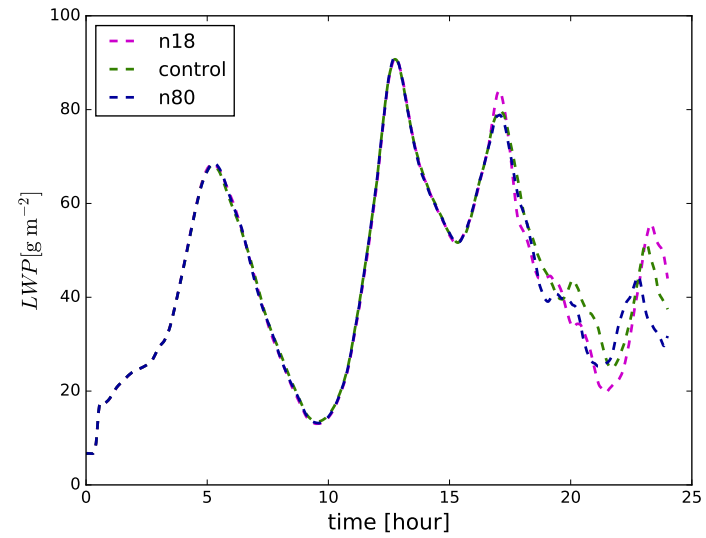

(b)

Figure A1. The LWP in the set for the sensitivity test to initial cloud droplet number in a) R05 and b) RF20 cases. Runs start with the same initial CCN concentration (ccn100), but different initial cloud droplet number concentrations (see A2). The value ranges were adapted to better show differences in the model ensembles, thus they differ between the left and the right column.

Table A1. the overview of results of sensitivity test to domain size and resolution

\begin{tabular}{|c|c|c|c|c|}
\hline \multirow[t]{2}{*}{ modified property: } & \multicolumn{4}{|c|}{ impact on: } \\
\hline & LWP & precipitation & $w_{e}$ & maximumofTKE \\
\hline control & $21.7 \mathrm{~g} \mathrm{~m}^{-2}$ & $0.07 \mathrm{~g} \mathrm{~m}^{-2} \mathrm{~s}^{-1}$ & $0.03 \mathrm{~ms}^{-1}$ & $2.2 m^{-2} s^{-2}$ \\
\hline domain size decreased to $\frac{1}{2}$ in both directions & $-8 \%$ & $+2 \%$ & $-10 \%$ & $-3 \%$ \\
\hline domain size doubled in both directions & $+1 \%$ & $+3 \%$ & $+1 \%$ & $-1 \%$ \\
\hline coarser horizontal resolution: $100 \mathrm{~m}$ & $-20 \%$ & $-15 \%$ & $+2 \%$ & $+11 \%$ \\
\hline finer horizontal resolution: $25 \mathrm{~m}$ & $+9 \%$ & $+37 \%$ & $-11 \%$ & $-9 \%$ \\
\hline coarser vertical resolution: regular $40 \mathrm{~m}$ grid & $+18 \%$ & $+60 \%$ & oscillations & $-11 \%$ \\
\hline finer vertical resolution: regular $25 \mathrm{~m}$ grid & $-6 \%$ & $-1 \%$ & $+7 \%$ & $+5 \%$ \\
\hline
\end{tabular}

The comparison of sensitivity runs with the control run. Differences are described relative to the control run at the time of the dropsonde launch. Dashes indicates no significant differences.

phase microphysics. JC performed the model simulations and the respective analysis of model output. JC prepared the manuscript, while RN supervised the process and revised the manuscript.

Competing interests. The authors declare that they have no conflict of interest. 
https://doi.org/10.5194/acp-2019-637

Preprint. Discussion started: 17 July 2019

(c) Author(s) 2019. CC BY 4.0 License.

(c) (1)

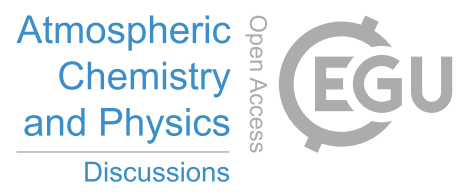

Acknowledgements. We gratefully acknowledge the funding by the Deutsche Forschungsgemeinschaft (DFG, German Research Foundation)

- Projektnummer 268020496 - TRR 172, within the Transregional Collaborative Research Center "ArctiC Amplification: Climate Relevant Atmospheric and SurfaCe Processes, and Feedback Mechanisms $(\mathcal{A C})^{3}$ ”. The Gauss Centre for Supercomputing e.V. (www.gauss-centre.eu)

595 is acknowledged for providing computing time on the GCS Supercomputer JUWELS at the Jülich Supercomputing Centre (JSC). We further thank the Alfred Wegener Institute (AWI), the PS106/1 crew and the ACLOUD science teams for making the field campaign happen. 


\section{References}

Ackerman, A. S., VanZanten, M. C., Stevens, B., Savic-Jovcic, V., Bretherton, C. S., Chlond, A., Golaz, J. C., Jiang, H., Khairoutdinov, M., Krueger, S. K. and Lewellen, D. C.: Large-eddy simulations of a drizzling, stratocumulus-topped marine boundary layer. Monthly Weather Review, 137 (3), 1083-1110, https://doi.org/10.1175/2008MWR2582.1, 2009.

Barton, N. P., Klein, S. A., and J. S. Boyle: On the Contribution of Longwave Radiation to Global Climate Model Biases in Arctic Lower Tropospheric Stability. Journal of Climate, 27, 7250-7269, https://doi.org/10.1175/JCLI-D-14-00126.1, 2014.

Bednorz, E., and Fortuniak, K.: Coreless winters in the European sector of the Arctic and their synoptic conditions, Pol. Polar Res., 33, 19-34, https://doi.org/10.2478/v10183-012-0007-2, https://doi.org/10.2478/v10183-012-0007-2, 2012.

Bretherton, C. S., Krueger, S. K., Wyant, M. C., Bechtold, P., Van Meijgaard, E., Stevens, B., and Teixeira, J.: A GCSS boundarylayer cloud model intercomparison study of the first ASTEX Lagrangian experiment, Boundary-Layer Meteorology, 93 (3), 341-380. https://doi.org/10.1023/A:1002005429969, 1999.

Bian, L., Ma, Y., Lu, C. and Lin, X.: The vertical structure of the atmospheric boundary layer over the central Arctic Ocean, Acta Oceanologica Sinica, 32 (10), 34-40, https://doi.org/10.1007/s13131-013-0363-8, 2013.

610 Bigg, E. K. and Leck, C.: The composition of fragments of bubbles bursting at the ocean surface, J. Geophys. Res., 113(D1), 1209, https://doi.org/10.1029/2007JD009078, 2008.

Birch, C. E., Brooks, I. M., Tjernström, M., Shupe, M. D., Mauritsen, T., Sedlar, J., Lock, A. P., Earnshaw, P., Persson, P. O. G., Milton, S. F., and Leck, C.: Modelling atmospheric structure, cloud and their response to CCN in the central Arctic: ASCOS case studies, Atmos. Chem. Phys., 12, 3419-3435, https://doi.org/10.5194/acp-12-3419-2012, 2012.

615 Blanchard, Y., Pelon, J., Eloranta, E. W., Moran, K. P., Delanoë, J., and Sèze, G.: A Synergistic Analysis of Cloud Cover and Vertical Distribution from A-Train and Ground-Based Sensors over the High Arctic Station Eureka from 2006 to 2010, J. Appl. Meteor. Climatol., 53, 2553-2570, https://doi.org/10.1175/JAMC-D-14-0021.1, 2014.

de Boer, G., Shupe, M. D., Caldwell, P. M., Bauer, S. E., Persson, O. Boyle, J. S., Kel- ley, M., Klein, S. A., and Tjernström, M.: Nearsurface meteorology during the Arc- tic Summer Cloud Ocean Study (ASCOS): evaluation of reanalyses and global climate models, Atmos. Chem. Phys., 14 (1), 427-445, https://doi.org/10.5194/acp-14-427-2014, 2014.

Brümmer, B.: Roll and Cell Convection in Wintertime Arctic Cold-Air Outbreaks, J. Atmos. Sci., 56, 2613-2636, https://doi.org/10.1175/1520-0469(1999)056<2613:RACCIW>2.0.CO;2, 1999.

Cai, Y., Montague, D. C., Mooiweer-Bryan, W., and Deshler, T.: Performance characteristics of the ultra high sensitiv- ity aerosol spectrometer for particles between 55 and $800 \mathrm{~nm}$ : Laboratory and field studies, J. Aerosol Sci., 39, 759-769, https://doi.org/10.1016/j.jaerosci.2008.04.007, 2008.

Caldwell, P., and Bretherton, C.S.: Large Eddy Simulation of the Diurnal Cycle in Southeast Pacific Stratocumulus, J. Atmos. Sci., 66, 432-449, https://doi.org/10.1175/2008JAS2785.1, 2009.

Cassano, J. J., DuVivier, A., Roberts, A., Hughes, M., Seefeldt, M., Brunke, M., Craig, A., Fisel, B., Gutowski, W., Hamman, J., Higgins, M., Maslowski, W., Nijssen, B., Osinski, R., and Zeng, X.: Development of the Regional Arctic System Model (RASM): Near-Surface Atmospheric Climate Sensitivity, J. Climate, 30, 5729-5753, https://doi.org/10.1175/JCLI-D-15-0775.1, 2017.

Cesana, G., Kay, J. E., Chepfer, H., English, J. M., and Boer, G.: Ubiquitous lowlevel liquidcontaining Arctic clouds: New observations and climate model constraints from CALIPSOGOCCP, Geophys. Res. Lett., 39, L20804, https://doi.org/10.1029/2012GL053385, 2012. 
Chechin, D. G. and Lüpkes, C.: Boundary-layer development and low-level baroclonicity during high-latitude cold-air outbreaks: A simple model, Boundary-Layer Meteorol., 162, 91-116, https://doi.org/10.1007/s10546-016-0193-2, 2017.

Chernokulsky, A. V., Esau, I., Bulygina, O. N., Davy, R., Mokhov, I. I., Outten, S., and Semenov, V. A.: Climatology and Interannual Variability of Cloudiness in the Atlantic Arctic from Surface Observations since the Late Nineteenth Century, J. Climate 30:6, 2103-2120, https://doi.org/10.1175/JCLI-D-16-0329.1, 2017

Corbetta, G., Orlandi, E., Heus, T., Neggers, R., and Crewell, S.: Overlap statistics of shallow boundary layer clouds: Comparing groundbased observations with largeeddy simulations, Geophys. Res. Lett., 42, 8185-8191, doi:10.1002/2015GL065140, 2015.

Costa, A., Meyer, J., Afchine, A., Luebke, A., Günther, G., Dorsey, J. R., Gallagher, M. W., Ehrlich, A., Wendisch, M., Baumgardner, D., Wex, H., and Krämer, M.: Classification of Arctic, midlatitude and tropical clouds in the mixed-phase temperature regime, Atmos. Chem. Phys., 17, 12219-12238, https://doi.org/10.5194/acp-17-12219-2017, 2017.

Cox, C. J., Turner, D. D., Rowe, P.M., Shupe, M. D., and Walden, V. P.: Cloud Microphysical Properties Retrieved from Downwelling Infrared Radiance Measurements Made at Eureka, Nunavut, Canada (2006-09). J. Appl. Meteor. Climatol., 53, 772-791, https://doi.org/10.1175/JAMC-D-13-0113.1, 2014.

Cox, C.J., Uttal, T., Long, C. N., Shupe, M. D., Stone, R. S., and Starkweather, S.: The Role of Springtime Arctic Clouds in Determining Autumn Sea Ice Extent. J. Climate, 29, 6581-6596, https://doi.org/10.1175/JCLI-D-16-0136.1, 2016.

Curry, J. A., Pinto, J. O., Benner, T., and Tschudi, M.: Evolution of the cloudy boundary layer during the autumnal freezing of the Beaufort Sea, J. Geophys. Res., 102( D12), 13851-13860, doi:10.1029/96JD03089., 1997.

Curry, J.A., Hobbs, P. V., King, M. D., Randall, D. A., Minnis, P., Isaac, G. A., Pinto, J. O., Uttal, T., Bucholtz, A., Cripe, D. G., Gerber, H., Fairall, C. W., Garrett, T. J., Hudson, J., Intrieri, J. M., Jakob, C., Jensen, T., Lawson, P., Marcotte, D., Nguyen, L., Pilewskie, P., Rangno, A., Rogers, D.C., Strawbridge, K. B., Valero, F. P., Williams, A. G., and Wylie, D.: FIRE Arctic Clouds Experiment. Bull. Amer. Meteor. Soc., 81, 5-30, https://doi.org/10.1175/1520-0477(2000)081<0005:FACE>2.3.CO;2, 2000.

Dagan, G., Koren, I., Altaratz, O. and Heiblum, R. H.: Aerosol effect on the evolution of the thermodynamic properties of warm convective cloud fields, Sci. Rep. 6, 38769, https://doi.org/10.1038/srep38769, 2016.

Dussen, J. J., Roode, S. R., Ackerman, A. S., Blossey, P. N., Bretherton, C. S., Kurowski, M. J., Lock, A. P., Neggers, R. A. J., Sandu, I., and Siebesma, A. P.: The GASS/EUCLIPSE model intercomparison of the stratocumulus transition as observed during ASTEX: LES results, J. Adv. Model. Earth Syst., 5, 483-499, doi:10.1002/jame.20033., 2013

Ehrlich, A., Wendisch, M., Lüpkes, C., Buschmann, M., Bozem, H., Chechin, D., Clemen, H.-C., Dupuy, R., Eppers, O., Hartmann, J., Herber, A., Jäkel, E., Järvinen, E., Jourdan, O., Kästner, U., Kliesch, L.-L., Köllner, F., Mech, M., Mertes, S., Neuber, R., RuizDonoso, E., Schnaiter, M., Schneider, J., Stapf, J., and Zanatta, M.: A comprehensive in situ and remote sensing data set from the Arctic CLoud Observations Using airborne measurements during polar Day (ACLOUD) campaign, Earth Syst. Sci. Data Discuss., https://doi.org/10.5194/essd-2019-96, in review, 2019.

Fan, S.M.: Modeling of observed mineral dust aerosols in the arctic and the impact on winter season lowlevel clouds, J. Geophys. Res. Atmos., 118, 11,161-11,174, doi:10.1002/jgrd.50842., 2013.

Fan, S.-M., Knopf, D. A., Heymsfield, A. J., and Donner, L. J.: Modeling of Aircraft Measurements of Ice Crystal Concentration in the Arctic and a Parameterization for Mixed-Phase Cloud, J. Atmos. Sci., 74, 3799-3814,https://doi.org/10.1175/JAS-D-17-0037.1.,2017

Field, P.R., Lawson, R.P., Brown, P.R., Lloyd, G., Westbrook, C., Moisseev, D., Miltenberger, A., Nenes, A., Blyth, A., Choularton, T. and Connolly, P.: Secondary ice production: Current state of the science and recommendations for the future, Meteorological Monographs, 58, 
Fleishauer, R. P., Larson, V. E., and Vonder Haar, T. H.: Observed microphysical structure of midlevel, mixed-phase clouds, J. Atmos. Sci., 59, 1779-1804, https://doi.org/10.1175/1520-0469(2002)059<1779:OMSOMM>2.0.CO;2, 2002.

Fletcher, J., Mason, S., and Jakob, C.: The Climatology, Meteorology, and Boundary Layer Structure of Marine Cold Air Outbreaks in Both Hemispheres, J. Climate, 29 (6), 1999-2014, https://doi.org/10.1175/JCLI-D-15-0268.1, 2016

Forbes, R. M., and Ahlgrimm, M.: On the Representation of High-Latitude Boundary Layer Mixed-Phase Cloud in the ECMWF Global Model, Mon. Weather Rev., 142, 3425-3445, https://doi.org/10.1175/MWR-D-13-00325.1, 2014.

Fridlind, A.M., van Diedenhoven, B., Ackerman, A. S., Avramov, A., Mrowiec, A., Morrison, H., Zuidema, P., and Shupe, M. D.: A FIREACE/SHEBA Case Study of Mixed-Phase Arctic Boundary Layer Clouds: Entrainment Rate Limitations on Rapid Primary Ice Nucleation Processes, J. Atmos. Sci., 69, 365-389, https://doi.org/10.1175/JAS-D-11-052.1, 2002.

Fridlind, A. M., Ackerman, A. S.: Simulations of Arctic Mixed-Phase Boundary Layer Clouds: Advances in Understanding and Outstanding Questions, In Mixed-Phase Clouds, Elsevier, 153-183, https://doi.org/10.1016/B978-0-12-810549-8.00007-6, 2018.

Fu, S. and Xue, H.: The Effect of Ice Nuclei Efficiency on Arctic Mixed-Phase Clouds from Large-Eddy Simulations, J. Atmos. Sci., 74, 3901-3913. https://doi.org/10.1175/JAS-D-17-0112.1, 2017.

Fu, S., Deng, X., Shupe, M.D. and Xue, H.: A modelling study of the continuous ice formation in an autumnal arctic mixed-phase cloud case, Atmospheric Research, 228, 77-85, https://doi.org/10.1016/j.atmosres.2019.05.021, 2019.

Graversen, R. G., Langen, P. L., and Mauritsen, T.: Polar amplification in CCSM4: Contributions from the lapse rate and surface albedo feedbacks, Journal of Climate, 27, 4433-4450, https://doi.org/10.1175/JCLI-D-13-00551.1, 2014.

Graversen, R. G., and Burtu, M.: Arctic amplification enhanced by latent energy transport of atmospheric planetary waves, Q.J.R.Meteorol.Soc. 142, 2046-2054, https://doi.org/10.1002/qj.2802, 2016.

Griewank, P. J., Schemann, V., and Neggers, R. A. J.: Evaluating and improving a PDF cloud scheme using high-resolution super-largedomain simulations, J. Adv. Model. Earth Sy., https://doi.org/10.1029/2018MS001421, 2018.

Gryschka, M., and Raasch, S.: Roll convection during a cold air outbreak: A large eddy simulation with stationary model domain, Geophys. Res. Lett., 32, L14805, https://doi.org/10.1029/2005GL022872, 2005.

Gryspeerdt, E., Stier, P., and Partridge, D. G.: Satellite observations of cloud regime development: The role of aerosol processes, Atmos. Chem. Phys., 14, 1141-1158, https://doi.org/10.5194/acp-14-1141-2014, 2014.

Gryspeerdt, E.Quaas, J., and N. Bellouin, 2016: Constraining the aerosol influence on cloud fraction, Journal of Geophysical Research: Atmospheres, 121, (7), (3566-3583).

Gryspeerdt, E., Sourdeval, O., Quaas, J., Delanoë, J. , Krämer, M., and Kühne, P.: Ice crystal number concentration estimates from lidarradar satellite remote sensing - Part 2: Controls on the ice crystal number concentration, Atmos. Chem. Phys., 18, 14351-14370, https://doi.org/10.5194/acp-18-14351-2018, 2018.

Hartmann, M., Blunier, T., Brügger, S. O., Schmale, J., Schwikowski, M., Vogel, A., Wex H., Stratmann, F.: Variation of ice nucleating particles in the European Arctic over the last centuries, Geophys. Res. Lett., 46, 4007-4016. https://doi.org/10.1029/2019GL082311, 2019.

Hashino, T., Satoh, M., Hagihara, Y., Kato, S., Kubota, T., Matsui, T., Nasuno, T., Okamoto, H., and Sekiguchi, M.: Evaluating Arctic cloud radiative effects simulated by NICAM with A-train, J. Geophys. Res. Atmos., 121, 7041-7063, https://doi.org/10.1002/2016JD024775, 2016. 
Heinze, R., Dipankar, A., Henken, C.C., Moseley, C., Sourdeval, O., Trömel, S., Xie, X., Adamidis, P., Ament, F., Baars, H. and Barthlott, C.: Largeeddy simulations over Germany using ICON: a comprehensive evaluation. Quarterly Journal of the Royal Meteorological Society, 143 (702), pp.69-100, https://doi.org/10.1002/qj.2947, 2017

Heus, T., van Heerwaarden, C. C., Jonker, H. J. J., Pier Siebesma, A., Axelsen, S., van den Dries, K., Geoffroy, O., Moene, A. F., Pino, D., de Roode, S. R., and Vilà-Guerau de Arellano, J.: Formulation of the Dutch Atmospheric Large-Eddy Simulation (DALES) and overview of its applications, Geosci. Model Dev., 3, 415-444, https://doi.org/10.5194/gmd-3-415-2010, 2010.

Holland, M. M. and Bitz, C. M.: Polar amplification of climate change in coupled models, Clim. Dyn., 21, 221-232. https://doi.org/10.1007/s00382-003-0332-6, 2003.

Ickes, L., Hoose, C. and Ekman, A.M.: Under which conditions do local marine sources influence Arctic mixed-phase clouds?, In EGU General Assembly Conference Abstracts, 20, 4-13 April, 2018 in Vienna, Austria, p. 15415, 2018.

Intrieri, J. M., Shupe, M. D., Uttal, T., and McCarty, B. J.: Annual cycle of Arctic cloud characteristics observed by radarand lidar at SHEBA, J. Geophys. Res., 107, 8030., https://doi.org/10.1029/2000JC000423, 2002.

Jackson, R. C., McFarquhar, G. M., Korolev, A. V., Earle, M. E., Liu, P. S. K., Lawson, R. P., Brooks, S., Wolde, M., Laskin, A., and Freer, M.: The dependence of ice microphysics on aerosol concentration in arctic mixedphase stratus clouds during ISDAC and MPACE, J. Geophys. Res., 117, D15207, https://doi.org/10.1029/2012JD017668, 2012.

Jakobson, E., Vihma, T., Palo, T., Jakobson, L., Keernik, H., and Jaagus, J.: Validation of atmospheric reanalyses over the central Arctic Ocean, Geophys.Res. Lett., 39 (10), https://doi.org/10.1029/2012GL051591, 2012.

Järvinen, E., Jourdan, O., Neubauer, D., Yao, B., Liu, C., Andreae, M. O., Lohmann, U., Wendisch, M., McFarquhar, G. M., Leisner, T., and Schnaiter, M.: Additional global climate cooling by clouds due to ice crystal complexity, Atmos. Chem. Phys., 18, 15767-15781, https://doi.org/10.5194/acp-18-15767-2018, 2018.

Jones, H. M., Young, G., Choularton, T. W., Bower, K. N., Lachlan-Cope, T., O’Shea, S., Dorsey, J., Ladkin, R., Kirchgaessner, A., and Weiss, A.: Summertime Arctic Aircraft Measurements during ACCACIA, Atmos. Chem. Phys. Discuss., https://doi.org/10.5194/acp-2018-283, 2018.

Jun, S.-Y., Ho, C.-H., Jeong, J.-H., Choi, Y.-S., and Kim, B.-M.: Recent changes in winter Arctic clouds and their relationships with sea ice and atmospheric conditions, Tellus A: Dynamic Meteorology and Oceanography, 68, 29130, https://doi.org/10.3402/tellusa.v68.29130, 2016.

Kanji, Z. A., Ladino, L. A., Wex, H., Boose, Y., Burkert-Kohn, M., Cziczo, D. J., and Krämer, M.: Overview of Ice Nucleating Particles, Meteorol. Monogr., 58, 1.1-1.33, https://doi.org/10.1175/AMSMONOGRAPHS-D-16-0006.1, 2017

Kalesse, H., de Boer, G., Solomon, A., Oue, M., Ahlgrimm, M., Zhang, D., Shupe, M. D., Luke, E., and Protat, A.: Understanding Rapid Changes in Phase Partitioning between Cloud Liquid and Ice in Stratiform Mixed-Phase Clouds: An Arctic Case Study, Mon. Wea. Rev., 144, 4805-4826, https://doi.org/10.1175/MWR-D-16-0155.1, 2016.

Kaul, C. M., Teixeira, J., and Suzuki, K.: Sensitivities in Large-Eddy Simulations of Mixed-Phase Arctic Stratocumulus Clouds Using a Simple Microphysics Approach. Mon. Wea. Rev., 143, 4393-4421, https://doi.org/10.1175/MWR-D-14-00319.1, 2015.

Kay, J. E., L'Ecuyer, T., Chepfer, H., Loeb, N., Morrison, A., and Cesana, G.: Recent advances in Arctic cloud and climate research, Curr. Clim. Change Rep., 2, 159-169, https://doi.org/10.1007/s40641-016-0051-9, 2016.

Khain, A. P., Rosenfeld D., Pokrovsky, A.: Simulating convective clouds with sustained supercooled liquid water down to - 37.5 C using a spectral microphysics model, Geophys. Res. Lett., 28, 3887-3890, https://doi.org/10.1029/2000GL012662, 2001. 
Khain, A. P., Beheng, K. D., Heymsfield, A., Korolev, A., Krichak, S. O., Levin, Z., Pinsky, M., Phillips, V., Prabhakaran, T.,Teller, A., van den Heever, S. C., and Yano, J.-I.: Representation of microphysical processes in cloud-resolving models: Spectral (bin) microphysics versus bulk parameterization. Rev. of Geophys., 53, 247-322. https://doi.org/10.1002/2014RG000468, 2015.

Khanal, S., and Wang, Z.: Uncertainties in MODIS-Based Cloud Liquid Water Path Retrievals at High Latitudes Due to Mixed-Phase Clouds and Cloud Top Height Inhomogeneity, J. of Geophysical Research: Atmospheres. 123, 11,154-11,172, https://doi.org/10.1029/2018JD028558, 2018.

Khvorostyanov, V. I., Curry, J. A., Pinto, J. O., Shupe, M., Baker, B. A., and Sassen, K.: Modeling with explicit spectral water and ice microphysics of a twolayer cloud system of altostratus and cirrus observed during the FIRE Arctic Clouds Experiment, J. Geophys. Res., 106( D14), 15099-15112, doi:10.1029/2000JD900521, 2001.

Kim, Y., Choi, Y. S., Kim, B. M. and Kim, H.: Influence of altered low cloud parameterizations for seasonal variation of Arctic cloud amount on climate feedbacks, Clim. Dyn., 47, 1661-1672, https://doi.org/10.1007/s00382-015-2926-1, 2016.

Klein, S. A., McCoy, R. B., Morrison, H. , Ackerman, A. S., Avramov, A., Boer, G. d., Chen, M. , Cole, J. N., Del Genio, A. D., Falk, M. , Foster, M. J., Fridlind, A. , Golaz, J. , Hashino, T. , Harrington, J. Y., Hoose, C. , Khairoutdinov, M. F., Larson, V. E., Liu, X. , Luo, Y., McFarquhar, G. M., Menon, S., Neggers, R. A., Park, S., Poellot, M. R., Schmidt, J. M., Sednev, I., Shipway, B. J., Shupe, M. D., Spangenberg, D. A., Sud, Y. C., Turner, D. D., Veron, D. E., Salzen, K. v., Walker, G. K., Wang, Z. , Wolf, A. B., Xie, S. , Xu, K. , Yang, F. and Zhang, G.: Intercomparison of model simulations of mixedphase clouds observed during the ARM MixedPhase Arctic Cloud Experiment. I: singlelayer cloud. Q.J.R. Meteorol. Soc., 135: 979-1002, https://doi.org/10.1002/qj.416, 2009.

Knudsen, E. M., Heinold, B., Dahlke, S., Bozem, H., Crewell, S., Gorodetskaya, I. V., Heygster, G., Kunkel, D., Maturilli, M., Mech, M., Viceto, C., Rinke, A., Schmithüsen, H., Ehrlich, A., Macke, A., Lüpkes, C., and Wendisch, M.: Meteorological conditions during the ACLOUD/PASCAL field campaign near Svalbard in early summer 2017, Atmos. Chem. Phys., 18, 17995-18022, https://doi.org/10.5194/acp-18-17995-2018, 2018.

Korolev, A., McFarquhar, G. M., Field, P. R., Franklin, C., Lawson, P., Wang, Z., and Wendisch, M.: Mixed-phase clouds: Progress and challenges, Meteorological Monographs, 58, 5.1-5.50., https://doi.org/10.1175/AMSMONOGRAPHS-D-17-0001.1, 2017.

van Laar, T. W., V. Schemann, V., and Neggers, R. A. J.: Investigating the Diurnal Evolution of the Cloud Size Distribution of Continental Cumulus Convection Using Multiday LES. J. Atmos. Sci., 76, 729-747, https://doi.org/10.1175/JAS-D-18-0084.1, 2019.

Lacour, A., Chepfer, H., Miller, N. B., Shupe, M. D., Noel, V., Fettweis, X., Gallee, H., Kay, J. E., Guzman, R., and Cole, J.: How Well Are Clouds Simulated over Greenland in Climate Models? Consequences for the Surface Cloud Radiative Effect over the Ice Sheet, J. Climate, 31, 9293-9312. https://doi.org/10.1175/JCLI-D-18-0023.1, 2018.

Lance, S., Shupe, M. D., Feingold, G., Brock, C. A., Cozic, J., Holloway, J. S., Moore, R. H., Nenes, A., Schwarz, J. P., Spackman, J. R., Froyd, K. D., Murphy, D. M., Brioude, J., Cooper, O. R., Stohl, A., and Burkhart, J. F.: Cloud condensation nuclei as a modulator of ice processes in Arctic mixed-phase clouds, Atmos. Chem. Phys., 11, 8003-8015, https://doi.org/10.5194/acp-11-8003-2011, 2011.

Leck, C. and Bigg, E. K.: A modified aerosol-cloud-climate feedback hypothesis, Environ. Chem., 4, 400-403, https://doi.org/10.1071/EN07061, 2007.

Lindsay, R., Wensnahan, M., Schweiger, A., and Zhang, J.: Evaluation of seven different atmospheric reanalysis products in the Arctic, J. Clim., 27(7), 2588-2606, https://doi.org/10.1175/JCLI-D-13-00014.1, 2014

Liu, A. Q., Moore, G. W. K., Tsuboki, K., and Renfrew, I. A.: A highresolution simulation of convective roll clouds during a coldair outbreak, Geophys. Res. Lett., 31, L03101, doi:10.1029/2003GL018530., 2004 
Liu, Y., Key, J. R., Ackerman, S. A., Mace, G. G., and Zhang, Q.: Arctic cloud macrophysical characteristics from CloudSat and CALIPSO, Remote Sens. Environ., 124, 159-173. https://doi.org/10.1016/j.rse.2012.05.006, 2012.

Liu, Y., Shupe, M. D., Wang, Z., and Mace, G.: Cloud vertical distribution from combined surface and space radar-lidar observations at two Arctic atmospheric observatories, Atmos. Chem. Phys., 17, 5973-5989, https://doi.org/10.5194/acp-17-5973-2017, 2017.

Loewe, K., Ekman, A. M. L., Paukert, M., Sedlar, J., Tjernström, M., and Hoose, C.: Modelling micro- and macrophysical contributors to the dissipation of an Arctic mixed-phase cloud during the Arctic Summer Cloud Ocean Study (ASCOS), Atmos. Chem. Phys., 17 (11), 6693-6704, https://doi.org/10.5194/acp-17-6693-2017, 2017.

Makshtas, A., Atkinson, D., Kulakov, M., Shutilin, S., Krishfield, R., and Proshutinsky, A.: Atmospheric forcing validation for modeling the central Arctic, Geophys.Res. Lett., 34(20), https://doi.org/10.1029/2007GL031378, 2007.

Mauritsen, T., Sedlar, J., Tjernström, M., Leck, C., Martin, M., Shupe, M., Sjogren, S., Sierau, B., Persson, P. O. G., Brooks, I. M., and Swietlicki, E.: An Arctic CCN-limited cloud-aerosol regime, Atmos. Chem. Phys., 11, 165-173, https://doi.org/10.5194/acp-11-165-2011, 2011.

McIlhattan, E. A., L'Ecuyer, T. S., and Miller, N. B.: Observational Evidence Linking Arctic Supercooled Liquid Cloud Biases in CESM to Snowfall Processes. J. Climate, 30, 4477-4495, https://doi.org/10.1175/JCLI-D-16-0666.1, 2017.

Mei, L., Rozanov, V., Jethva, H., Meyer, K.G., Lelli, L., Vountas, M. and Burrows, J.P.: Extending XBAER Algorithm to Aerosol and Cloud Condition, IEEE Transactions on Geoscience and Remote Sensing, https://doi.org/10.1109/TGRS.2019.2919910, 2019.

Mertes, S.; Kästner, U., Macke, A.: Airborne in-situ measurements of the aerosol absorption coefficient, aerosol particle number concentration and size distribution of cloud particle residuals and ambient aerosol particles during the ACLOUD campaign in May and June 2017, Leibniz-Institut für Troposphärenforschung e.V., Leipzig, PANGAEA, https://doi.org/10.1594/PANGAEA.900403, 2019.

Mioche, G., Jourdan, O., Delanoë, J., Gourbeyre, C., Febvre, G., Dupuy, R., Monier, M., Szczap, F., Schwarzenboeck, A., and Gayet, J.-F.: Vertical distribution of microphysical properties of Arctic springtime low-level mixed-phase clouds over the Greenland and Norwegian seas, Atmos. Chem. Phys., 17, 12845-12869, https://doi.org/10.5194/acp-17-12845-2017, 2017.

Morrison, H., Zuidema, P., Ackerman, A.S., Avramov, A., De Boer, G., Fan, J., Fridlind, A.M., Hashino, T., Harrington, J.Y., Luo, Y. and Ovchinnikov, M.: ntercomparison of cloud model simulations of Arctic mixedphase boundary layer clouds observed during SHEBA/FIREACE, J. Adv. Model. Earth Syst., 3, M05001, doi:10.1029/2011MS000066, 2011.

Morrison, H., de Boer, G., Feingold, G., Harrington, J., Shupe, M. D., and Sulia, K.: Resilience of persistent Arctic mixedphase clouds, Nature Geoscience, 5, 11-17, https://doi.org/10.1038/ngeo1332, 2012.

Morrison, A. L., Kay, J. E., Chepfer, H., Guzman, R. and Yettella, V.: Isolating the liquid cloud response to recent Arctic sea ice variability using spaceborne lidar observations. Journal of Geophysical Research: Atmospheres, 123, 473-490. https://doi.org/10.1002/2017JD027248, 2018.

Morrison, A. L., Kay, J. E., Frey, W. R., Chepfer, H., and Guzman, R.: Cloud response to Arctic Sea ice loss and implications for future feedback in the CESM1 climate model. Journal of Geophysical Research: Atmospheres, 124, 1003-1020. https://doi.org/10.1029/2018JD029142. 2019.

Müller, G., B. Brümmer, and Alpers, W.: Roll Convection within an Arctic Cold-Air Outbreak: Interpretation of In Situ Aircraft Measurements and Spaceborne SAR Imagery by a Three-Dimensional Atmospheric Model. Mon. Wea. Rev., 127, 363-380, https://doi.org/10.1175/1520-0493(1999)127<0363:RCWAAC>2.0.CO;2, 1999.

Neggers, R. A. J., Ackerman, A. S., Angevine, W. M., Bazile, E., Beau, I., Blossey, P. N., Boutle, I. A., de Bruijn, C., Cheng, A., van der Dussen, J., Fletcher, J., Dal Gesso, S., Jam, A., Kawai, H., Cheedela, S. K., Larson, V. E., Lefebvre, M.-P., Lock, A. P., Meyer, N. R., de 
Roode, S. R., de Rooy, W., Sandu, I., Xiao, H., and Xu, K.-M.: Single-Column Model Simulations of Subtropical Marine Boundary-Layer

Neggers, R. A. J., Chylik, J., Egerer, U., Griesche, H., Schemann, V., Seifert, P., Siebert, H. and Macke,A.: Local and remote controls on Arctic mixed-layer evolution, accepted for publication in J. Adv. Mod. Earth Syst., 11, https://doi.org/10.1029/2019MS001671, 2019.

Norgren, M. S., de Boer, G., and Shupe, M. D.: Observed aerosol suppression of cloud ice in low-level Arctic mixed-phase clouds, Atmos. Chem. Phys., 18, 13345-13361, https://doi.org/10.5194/acp-18-13345-2018, 2018.

Nygård, T., Valkonen, T. and Vihma, T.: Characteristics of Arctic low-tropospheric humidity inversions based on radio soundings, Atmos. Chem. Phys., 14, 1959-1971. https://doi.org/10.5194/acp-14-1959-2014, 2014.

Ouwersloot, H., Moene, A.F., Attema, J., and Arellano, J.: Large-Eddy Simulation Comparison of Neutral Flow Over a Canopy: Sensitivities to Physical and Numerical Conditions, and Similarity to Other Representations, Boundary-Layer Meteorol, 162: 71, https://doi.org/10.1007/s10546-016-0182-5, 2016.

Ovchinnikov, M., Korolev, A., and Fan, J.: Effects of ice number concentration on dynamics of a shallow mixedphase stratiform cloud, J. Geophys. Res., 116, D00T06, doi:10.1029/2011JD015888, 2011.

Ovchinnikov, M., Ackerman, A. S., Avramov, A., Cheng, A., Fan, J., Fridlind, A. M., Ghan, S., Harrington, J., Hoose, C., Korolev, A., McFarquhar, G. M., Morrison, H., Paukert, M., Savre, J., Shipway, B. J., Shupe, M. D., Solomon, A., and Sulia, K.: Intercomparison of largeeddy simulations of Arctic mixedphase clouds: Importance of ice size distribution assumptions, J. Adv. Model. Earth Syst., 6, 223-248, https://doi.org/10.1002/2013MS000282, 2014.

Overland, J., Dethloff, K., Francis, J., Hall, R., Hanna, E., Kim, S.-J., Screen, J., Shepherd, T., and Vihma, T.: Nonlinear Response of Mid-latitude Weather to the Changing Arctic, Nature Clim. Change, 6, 992-999, https://doi.org/10.1038/nclimate3121, 2016.

Overpeck, J., Hughen, K., Hardy, D., Bradley, R., Case, R., Douglas, M., Finney, B., Gajewski, K., Jacoby, G., Jennings, A., Lamourex, S., Lasca, A., MacDonald, G., Moore, J., Retelle, M., Smith, S., Wolfe, A., and Zielinski, G.: Arctic environmental change of the last four centuries, Science, 278, 1251-1256., https://doi.org/10.1126/science.278.5341.1251, 1997.

Pithan, F. and Mauritsen, T.: Arctic amplification dominated by temperature feedbacks in contemporary climate models, Nature Geoscience, 7, 181-184, https://doi.org/10.1038/ngeo2071, 2014.

Pithan, F., Ackerman, A., Angevine, W. M., Hartung, K., Ickes, L., Kelley, M., Medeiros, B., Sandu, I., Steeneveld, G.-J., Sterk, H. A. M., Svensson, G., Vaillancourt, P. A., and Zadra, A.: Select strengths and biases of models in representing the Arctic winter boundary layer over sea ice: the Larcform 1 single column model intercomparison, J. Adv. Mod. Earth Syst., 8, 1345-1357, https://doi.org/10.1002/2016MS000630, 2016.

Pithan, F., Svensson, G., Caballero, R., Chechin, D., Cronin, T. W., Ekman, A. M. L., Neggers, R. A. J., Shupe, M. D., Solomon, A., Tjernström, M., and Wendisch, M.: Role of air-mass transformations in exchange between the Arctic and mid-latitudes, Nature Geoscience, 11, 805-812, https://doi.org/10.1038/s41561-018-0234-1, 2018.

Prenni, A.J., Harrington, J.Y., Tjernström, M., DeMott, P.J., Avramov, A., Long, C.N., Kreidenweis, S.M., Olsson, P.Q. and Verlinde, J.: Can ice-nucleating aerosols affect arctic seasonal climate?. Bulletin of the American Meteorological Society, 884, 541-550, https://doi.org/10.1175/BAMS-88-4-541, 2007.

Qiu, S., Xi, B., and Dong, X.: Influence of wind direction on thermodynamic properties and Arctic mixedphase clouds in autumn at Utqiagivik, Alaska, J. Geophys. Res.: Atmospheres, 123, 9589-9603, https://doi.org/10.1029/2018JD028631, 2018.

855 Rangno, A. L. and Hobbs, P. V.: Ice particles in stratiform clouds in the Arctic and possible mechanisms for the production of high ice concentrations, J. Geophys. Res., 106 (D14), 15065-15075, https://doi.org/10.1029/2000JD900286, 2001. 
Reisner, J., Rasmussen, R. M., Bruintjes, R. T.: Explicit forecasting of supercooled liquid water in winter storms using the MM5 mesoscale model. Quart. J. Roy. Meteor. Soc., 124, 1071-1107, 1998.

Richardson, Y. P., Droegemeier, K. K., and Davies-Jones, R. P.: The influence of horizontal environmental variability on numerically simulated convective storms. Part I: Variations in vertical shear, Mon. Wea. Rev., 135, 3429-3455, https://doi.org/10.1175/MWR3463.1, 2007.

De Roode, S.R., Siebesma, A.P., Jonker, H.J. and de Voogd, Y.: Parameterization of the vertical velocity equation for shallow cumulus clouds, Mon. Wea. Rev., 140, 2424-2436, https://doi.org/10.1175/MWR-D-11-00277.1, 2012.

de Roode, S.R., Sandu, I., van der Dussen, J. J., Ackerman, A. S., Blossey, P., Jarecka, D., Lock, A., Siebesma, A. P., and Stevens, B.: LargeEddy Simulations of EUCLIPSE-GASS Lagrangian Stratocumulus-to-Cumulus Transitions: Mean State, Turbulence, and Decoupling. J. Atmos. Sci., 73, 2485-2508, https://doi.org/10.1175/JAS-D-15-0215.1, 2016.

de Roode, S.R., Frederikse, T., Siebesma, A., Ackerman, A.S., Chylik, J., Field, P., Fricke, J., Gryschka, M., Hill, A., Honnert, R. and Krueger, S.: Turbulent transport in the Gray Zone: A largeeddy model intercomparison study of the CONSTRAIN cold air outbreak case, J. Adv. Model. Earth Syst., 11, 597-623. https://doi.org/10.1029/2018MS001443, 2019.

Sand, M., Samset, B. H., Balkanski, Y., Bauer, S., Bellouin, N., Berntsen, T. K., Bian, H., Chin, M., Diehl, T., Easter, R., Ghan, S. J., Iversen, T., Kirkevåg, A., Lamarque, J.-F., Lin, G., Liu, X., Luo, G., Myhre, G., Noije, T. V., Penner, J. E., Schulz, M., Seland, Ø., Skeie, R. B., Stier, P., Takemura, T., Tsigaridis, K., Yu, F., Zhang, K., and Zhang, H.: Aerosols at the poles: an AeroCom Phase II multi-model evaluation, Atmos. Chem. Phys., 17, 12197-12218, https://doi.org/10.5194/acp-17-12197-2017, 2017.

Sandu, I., and Stevens, B.: On the Factors Modulating the Stratocumulus to Cumulus Transitions, J. Atmos. Sci., 68, 1865-1881, https://doi.org/10.1175/2011JAS3614.1., 2011.

Schäfer, M., Loewe, K., Ehrlich, A., Hoose, C., and Wendisch, M.: Simulated and observed horizontal inhomogeneities of optical thickness of Arctic stratus, Atmos. Chem. Phys., 18, 13115-13133, https://doi.org/10.5194/acp-18-13115-2018, 2018.

Schulz, H., Zanatta, M., Bozem, H., Leaitch, W. R., Herber, A. B., Burkart, J., Willis, M. D., Kunkel, D., Hoor, P. M., Abbatt, J. P. D., and Gerdes, R.: High Arctic aircraft measurements characterising black carbon vertical variability in spring and summer, Atmos. Chem. Phys., 19, 2361-2384, https://doi.org/10.5194/acp-19-2361-2019, 2019.

Schweiger, A. J., Lindsay, R. W., Francis, J. A., Key, J., Intrieri, J. M., and Shupe, M. D., Validation of TOVS PathP data during SHEBA, J. Geophys. Res., 107( C10), 8041, https://doi.org/10.1029/2000JC000453, 2002.

A. Seifert, and Beheng, K. D.: A two-moment cloud microphysics parameterization for mixed-phase clouds. Part 1: Model description, Meteorol. Atmos. Phys., 92, 45-66, https://doi.org/10.1007/s00703-005-0112-4, 2006a.

Seifert, A. and Beheng, K. D.: A two-moment cloud microphysics parameterization for mixed-phase clouds. Part 2: Maritime vs. continental deep convective storms, Meteorology and Atmospheric Physics, 92, 67-82, https://doi.org/10.1007/s00703-005-0113-3, 2006b.

Seifert, A., Heus, T., Pincus, R., Stevens, B.: Largeeddy simulation of the transient and nearequilibrium behavior of precipitating shallow convection, J. Adv. Model. Earth Syst., 7, 1918-1937, https://doi.org/10.1002/2015MS000489, 2015.

Serreze, M. C., Maslanik, J. A., Scambos, T. A., Fetterer, F., Stroeve, J., Knowles, K., Fowler, C., Drobot, S., Barry, R. G., and Haran, T. M.: A record minimum Arctic sea ice extent an area in 2002, Geophys. Res. Lett. 30, 1110, https://doi.org/10.1029/2002GL016406, 2003.

Serreze, M. C., and Francis, J. A.: The Arctic amplification debate, J. A. Climatic change, 76, 241-264, https://doi.org/10.1007/s10584-0059017-y, 2006.

Shupe, M. D., Uttal, T., and Matrosov, S. Y.: Arctic cloud microphysics retrievals from surface-based remote sensors at SHEBA, J. Appl. Meteor., 44, 1544-1562, https://doi.org/10.1175/JAM2297.1, 2005. 
Simjanovski, D., Girard, E., and Du, P.: An Evaluation of Arctic Cloud and Radiation Processes Simulated by the https://doi.org/10.1080/07055900.2011.604266, 2011.

Skyllingstad E.D., and Edson, J.B.: Large-Eddy Simulation of Moist Convection during a Cold Air Outbreak over the Gulf Stream, J. Atmos. Sci., 66, 1274-1293, https://doi.org/10.1175/2008JAS2755.1, 2009.

Small, R. J., Xie, S-P., Wang, Y., Esbensen, S. K., and D. Vickers, D.: Numerical Simulation of Boundary Layer Structure and CrossEquatorial Flow in the Eastern Pacific, J. Atmos. Sci., 62, 1812-1830., https://doi.org/10.1175/JAS3433.1, 2005.

Solomon, A., Morrison, H., Persson, O., Shupe, M. D., and Bao, J. W.: Investigation of microphysical parameterizations of snow and ice in Arctic clouds during M-PACE through model-observation comparisons, Mon. Weather Review, 137, 3110-3128.

Solomon, A., Boer, G.D., Creamean, J.M., McComiskey, A., Shupe, M.D., Maahn, M. and Cox, C.,: The relative impact of cloud condensation nuclei and ice nucleating particle concentrations on phase partitioning in Arctic mixed-phase stratocumulus clouds, Atmospheric Chemistry and Physics, 18 (23), 17047-17059, https://doi.org/10.1175/2009MWR2688.1, 2018.

Sotiropoulou, G., Sedlar, J., Forbes, R. and Tjernström, M.: Summer Arctic clouds in the ECMWF forecast model: An evaluation of cloud parametrization schemes, Quart. J. Roy. Meteor. Soc., 142 (694), 387-400, https://doi.org/10.1002/qj.2658, 2016.

Sotiropoulou, G., Tjernström, M. Savre, J., Ekman, A. M. L., Hartung, K., and Sedlar, J.: Large-eddy simulation of a warm-air advection episode in the summer Arctic, Q. J. Roy. Meteorol. Soc., 144(717), 2449-2462, doi:10.1002/qj.3316., 2018.

910 Sotiropoulou, G., Bossioli, E., and Tombrou, M.: Modeling extreme warmair advection in the Arctic: The role of microphysical treatment of cloud droplet concentration, J. Geophys. Res.: Atmospheres, 124, 3492- 3519, https://doi.org/10.1029/2018JD029252, 2019.

Stevens, R. G., Loewe, K., Dearden, C., Dimitrelos, A., Possner, A., Eirund, G. K., Raatikainen, T., Hill, A. A., Shipway, B. J., Wilkinson, J., Romakkaniemi, S., Tonttila, J., Laaksonen, A., Korhonen, H., Connolly, P., Lohmann, U., Hoose, C., Ekman, A. M. L., Carslaw, K. S., and Field, P. R.: A model intercomparison of CCN-limited tenuous clouds in the high Arctic, Atmos. Chem. Phys., 18, 11041-11071, https://doi.org/10.5194/acp-18-11041-2018, 2018.

Struthers, H., Ekman, A. M. L., Glantz, P., Iversen, T., Kirkevåg, A., Mårtensson, E. M., Seland, Ø., and Nilsson, E. D.: The effect of sea ice loss on sea salt aerosol concentrations and the radiative balance in the Arctic, Atmos. Chem. Phys. Discuss., 10, 28859-28908., https://doi.org/10.5194/acpd-10-28859-2010, 2010.

Sullivan, S. C. , Hoose C., and Nenes, A.: Investigating the contribution of secondary ice production to incloud ice crystal numbers, J. Geophys. Res.: Atmospheres, 122, 17, 9391-9412, https://doi.org/10.1002/2017JD026546, 2017.

De Szoeke, S. P., and Bretherton, C. S.: Quasi-Lagrangian large eddy simulations of cross-equatorial flow in the east Pacific atmospheric boundary layer, J. Atmos. Sci., 61 (15), 1837-1858, 2004.

Tan, I., and Storelvmo, T.: Sensitivity study on the influence of cloud microphysical parameters on mixed-phase cloud thermodynamic phase partitioning in CAM5, Journal of the Atmospheric Sciences, 73, 709-728, https://doi.org/10.1175/JAS-D-15-0152.1, 2016.

Tan, I., and Storelvmo, T.: Evidence of Strong Contributions From MixedPhase Clouds to Arctic Climate Change, Geophys. Res. Lett., 46 (5), 2894-2902, https://doi.org/10.1029/2018GL081871, 2019a.

Tan, I., Oreopoulos, L., and Cho, N.: The Role of Thermodynamic Phase Shifts in Cloud Optical Depth Variations With Temperature, Geophys. Res. Lett., 46 (8), 4502-4511, https://doi.org/10.1029/2018GL081590, 2019b.

Tjernström, M., Shupe, M. D., Brooks, I. M., Persson P. O G. Prytherch, J., Salisbury, D. J., Sedlar, J., Achtert, P., Brooks, B. J., Johnston, P. E., Sotiropoulou, G.,and Wolfe, D.: Warm-air advection, air mass transformation and fog causes rapid ice melt, GRL. 42., https://doi.org/10.1002/2015GL064373, 2015. 
Tjernström, M., Shupe, M. D., Brooks, I. M., Achtert, P., Prytherch, J., and Sedlar, J.: Arctic Summer Airmass Transformation, Surface Inversions, and the Surface Energy Budget, J. Climate, 32:3, 769-789. https://doi.org/10.1175/JCLI-D-18-0216.1, 2019.

Tomas, J.M., Pourquie, M.J.B.M. and Jonker, H. J. J.: The influence of an obstacle on flow and pollutant dispersion in neutral and stable boundary layers, Atmospheric Environment, 113, 236-246., https://doi.org/10.1016/j.atmosenv.2015.05.016, 2015.

Tsay, S.-C. and Jayaweera, K.: Physical characteristics of Arctic stratus clouds, J. Clim. Appl. Meteorol., 23, 584596,https://doi.org/10.1175/1520-0450(1984)023<0584:PCOASC>2.0.CO;2, 1984.

Tsay, S. C., K. Stamnes, and Jayaweera, K.: Radiative energy budget in the cloudy and hazy Arctic, J. Atmos. Sci., 46 (7), 1002-1018, https://doi.org/10.1175/1520-0469(1989)046<1002:REBITC>2.0.CO;2, 1989.

Várnai, T., and Marshak, A.: Global CALIPSO observations of aerosol changes near clouds, IEEE Geosci. Remote Sens. Lett., 8 (1), 19-23, https://doi.org/10.1109/LGRS.2010.2049982, 2011.

Vassel, M., Ickes, L., Maturilli, M., and Hoose, C.: Classification of Arctic multilayer clouds using radiosonde and radar data in Svalbard, Atmos. Chem. Phys., 19, 5111-5126, https://doi.org/10.5194/acp-19-5111-2019, 2019.

Vavrus, S., Holland, M. M., and Bailey, D. A.: Changes in Arctic clouds during intervals of rapid sea ice loss. Climate Dynamics, 36, 1475-1489, https://doi.org/10.1007/s00382-010-0816-0, 2011.

Verlinde, J., Harrington, J. Y., McFarquhar, G. M., Yannuzzi, V. T., Avramov, A., Greenberg, S., Johnson, N., Zhang, G., Poellot, M. R., Mather, J. H., Turner, D. D., Eloranta, E. W., Zak, B. D., Prenni, A. J., Daniel, J. S., Kok, G. L., Tobin, D. C., Holz, R., Sassen, K., Spangenberg, D., Minnis, P., Tooman, T. P., Ivey, M. D., Richardson, S. J., Bahrmann, C. P., Shupe, M. D., DeMott, P. J., Heymsfield, A. J., and Schofield, R.: The mixed-phase arctic cloud experiment, Bull. Amer. Meteor. Soc., 88 (2), 205-222, doi:10.1175/BAMS-88-2-205, 2007.

Vihma, T., Pirazzini, R., Fer, I., Renfrew, I.A., Sedlar, J., Tjernström, M., Lüpkes, C., Nygard, T., Notz, D., Weiss, J. and Marsan, D.: Advances in understanding and parameterization of small-scale physical processes in the marine Arctic climate system: a review, Atmos. Chem. Phys., 14, 9403-9450, https://doi.org/10.5194/acp-14-9403-2014, 2014.

Walsh, J. E., and Crane, R. G.: A comparison of GCM simulations of Arctic climate, Geophysical research letters, 19 (1), 29-32, https://doi.org/10.1029/91GL03004, 1992.

Wendisch, M., Yang, P. and Ehrlich, A.: Amplified climate changes in the Arctic: Role of clouds and atmospheric radiation, Sitzungsberichte der Sachsischen Akademie der Wissenschaften zu Leipzig, Mathematisch-Naturwissenschaftliche Klasse, 132 (3), 1-34, 2013.

Wendisch, M., Brückner, M., Burrows, J. P., Crewell, S., Dethloff, K., Ebell, K., Lüpkes, C., Macke, A., Notholt, J., Quaas, J., Rinke, A., and Tegen, I.: Understanding causes and effects of rapid warming in the Arctic, Eos, 98, https://doi.org/10.1029/2017EO064803, 2017.

Wendisch, M., Macke, A., Ehrlich, A., Lüpkes, C., Mech, M., Chechin, D., Dethloff, K., Velasco, C. B., Bozem, H., Brückner, M., Clemen, H., Crewell, S., Donth, T., Dupuy, R., Ebell, K., Egerer, U., Engelmann, R., Engler, C., Eppers, O., Gehrmann, M., Gong, X., Gottschalk, M., Gourbeyre, C., Griesche, H., Hartmann, J., Hartmann, M., Heinold, B., Herber, A., Herrmann, H., Heygster, G., Hoor, P., Jafariserajehlou, S., Jäkel, E., Järvinen, E., Jourdan, O., Kästner, U., Kecorius, S., Knudsen, E. M., Köllner, F., Kretzschmar, J., Lelli, L., Leroy, D., Maturilli, M., Mei, L., Mertes, S., Mioche, G., Neuber, R., Nicolaus, M., Nomokonova, T., Notholt, J., Palm, M., van Pinxteren, M.,

Quaas, J., Richter, P., Ruiz-Donoso, E., Schäfer, M., Schmieder, K., Schnaiter, M., Schneider, J., Schwarzenböck, A., Seifert, P., Shupe, M. D., Siebert, H., Spreen, G., Stapf, J., Stratmann, F., Vogl, T., Welti, A., Wex, H., Wiedensohler, A., Zanatta, M., and Zeppenfeld, S.: The Arctic Cloud Puzzle: Using ACLOUD/PASCAL Multiplatform Observations to Unravel the Role of Clouds and Aerosol Particles in Arctic Amplification. Bull. Amer. Meteor. Soc., 100, 841-871, https://doi.org/10.1175/BAMS-D-18-0072.1, 2019. 
https://doi.org/10.5194/acp-2019-637

Preprint. Discussion started: 17 July 2019

(c) Author(s) 2019. CC BY 4.0 License.

(c) (P)
Atmospheric

Chemistry

and Physics

Discussions

Wesslén, C., Tjernström, M., Bromwich, D. H., de Boer, G., Ekman, A. M. L., Bai, L.-S., and Wang, S.-H.: The Arctic summer atmosphere: an evaluation of reanalyses using ASCOS data, Atmos. Chem. Phys., 14 (5), 2605-2624, doi:10.5194/acp-14-2605-2014, 2014.

Wex, H., Huang, L., Zhang, W., Hung, H., Traversi, R., Becagli, S., Sheesley, R., Moffett, C., Barrett, T., Bossi, R., Skov, H., Hünerbein, A., Lubitz, J., Löffler, M., Linke, O., Hartmann, M., Herenz, P., and Stratmann, F.: Annual variability of ice nucleating particle concentrations at different Arctic locations, Atmos. Chem. Phys., 19, 5293-5311, https://doi.org/10.5194/acp-19-5293-2019, 2019.

Willis, M. D., Leaitch, W. R., and Abbatt, J. P. D.: Processes Controlling the Composition and Abundance of Arctic Aerosol. Reviews of Geophysics 56:4, 621-671, https://doi.org/10.1029/2018RG000602, 2018.

Willis, M.D., Bozem, H., Kunkel, D., Lee, A. K. Y., Schulz, H., Burkart, J., Aliabadi, A. A., Herber, A. B., Leaitch, W. R., and Abbatt, J. P. D.: Aircraft-based measurements of High Arctic springtime aerosol show evidence for vertically varying sources, transport and composition, Atmos. Chem. Phys., 19, 57-76, https://doi.org/10.5194/acp-19-57-2019, 2019.

Young, G., Jones, H. M., Choularton, T., Crosier, J., Bower, K. N., Gallagher, M. W., Davies, R. S., Renfrew, I., Elvidge, A., Darbyshire, E., Marenco, F., Brown, P. R. A., Ricketts, H. M. A., Connolly, P., Lloyd, G., Williams, P. I., Allan, J. D., Taylor, J. W., Liu, D. and Flynn, M. J.: Observed microphysical changes in Arctic mixed-phase clouds when transitioning from sea ice to open ocean, Atmos. Chem. Phys., 16, 13945-13967, https://doi.org/10.5194/acp-16-13945-2016, 2016.

Young, G., Connolly, P. J., Dearden, C., Choularton, T. W.: Relating large-scale subsidence to convection development in Arctic mixed-phase marine stratocumulus, Atmos. Chem. Phys., 18, 1475-1494., https://doi.org/10.5194/acp-18-1475-2018, 2018.

Zamora, L. M., Kahn, R. A., Eckhardt, S., McComiskey, A., Sawamura, P., Moore, R., and Stohl, A.: Aerosol indirect effects on the nighttime Arctic Ocean surface from thin, predominantly liquid clouds, Atmos. Chem. Phys., 17:12, 7311-7332, https://doi.org/10.5194/acp-177311-2017, 2017.

Zamora, L. M., Kahn, R. A., Huebert, K. B., Stohl, A., Eckhardt, S.: A satellite-based estimate of combustion aerosol cloud microphysical effects over the Arctic Ocean, Atmos. Chem. Phys., 18, 14949-14964., https://doi.org/10.5194/acp-18-14949-2018, 2018. 